\title{
Wealth, Financial Intermediation and Growth
}

\author{
Alejandro Gaytan \\ Romain Ranciere \\ New York University and Banco de Mexico \\ CREI and Universitat Pompeu Fabra
}

\section{A pril 2004}

(first draft: January 2004)

\begin{abstract}
This paper presents empirical support for the existence of wealth effects in the contribution of financial intermediation to economic growth, and offers a theoretical explanation for these effects. Using GMM dynamic panel data techniques applied to study the growth-promoting effects of financial intermediation, we show that the exogenous contribution of financial development on economic growth has different effects for different levels of income per capita. We find that this contribution is generally increasing with the level of income per capita of the economy, up to a relatively high level of income. This contribution is consistently lower for poor countries; and for some low levels of income per capita it can be negative. We provide a model to account for these wealth effects. The model is a overlapping generations growth model where financial intermediaries implement liquidity risk sharing among depositors. We show that at early stages of economic development, a bank can increase welfare of its depositors only at the cost of lowering investment and growth. However, once the economy has crossed certain wealth threshold, the liquidity role of banks becomes unambiguously growth enhancing. As wealth increases, banks offer improving liquidity insurance, and higher growth; however, for high levels of wealth, growth generated by financial intermediation declines as the economy attains the optimal level of consumption risk sharing.
\end{abstract}

KEYWORDS: Financial development, Economic growth, OLG growth models, Liquidity, financial intermediation.

JEL Codes: E44, G21, O16, O40 


\section{Introduction.}

In recent years the relationship between financial development and economic growth has received close attention in the literature. A large number of empirical studies support the existence of a positive relationship between financial intermediation and growth. ${ }^{1}$ King and Levine $(1993$ a,b), show that financial development is a good predictor of future growth. More recently, Levine, et.al. (2000) and Beck et.al. (2000) use an external instrumental variables estimation, and a GMM dynamic panel data estimation to overcome potential problems of endogeneity of financial development, and confirm the existence of a strong, positive contribution of the exogenous component of financial development to economic growth. However, most of these studies assume a uniform financial intermediation-growth relationship and, although panel data estimations, such as Levine et.al. (2000), Benhabib and Spiegel (2000), etc., control for unobserved country specific effects, there can be country-group characteristics that generate an asymmetric effect of financial intermediation on growth. De Gregorio and Guidotti (1995), for example, show that in a panel regression for Latin American countries financial intermediation is negatively linked with economic growth, and suggest that these results may reflect the negative effect of financial crises experienced by several countries in the region.

The empirical information of financial development provides initial evidence that the growth benefits of financial intermediation differ with the level of wealth of the economy. Table 1 summarizes information on financial development and growth, it orders countries in quartiles according with real per capita income growth over the period 1970-2000. For each group, it displays the percent variation of financial depth, as well as the mean of initial and final income. Table 1 confirms the positive relationship between growth performance and financial development. Moreover, those countries that grew faster had a joint high performance of growth and financial development, and are typically middle-income economies who have "emerged" during the period. At the other end, in the first quartile, we find countries that have experienced declines in per capita income during the period along with poor financial development. This suggest that financial intermediation plays a crucial role in the growth performance of middle-income "emerging" economies, and the possibility of wealth effects on this relationship.

\footnotetext{
${ }^{1}$ See for example Levine and Zervos (1996) and Benhabib and Spiegel (2000). Levine (1997) provides a good summary of financial development-growth literature.
} 
Table 1: Financial Development and Real Per Capita Growth (1970-2000)

\begin{tabular}{|c|c|c|c|c|c|}
\hline Growth Quartile & $\begin{array}{l}\text { Average Annual } \\
\text { Growth }\end{array}$ & $\begin{array}{c}\text { Financial } \\
\text { Development. Private } \\
\text { Credit }^{2}(\%)\end{array}$ & $\begin{array}{c}\text { Financial } \\
\text { Development. Liquid } \\
\text { Liabilities }^{2}(\%)\end{array}$ & $\begin{array}{c}\text { Initial Income } \\
\text { per Capita }\end{array}$ & $\begin{array}{c}\text { Final Income } \\
\text { per Capita }^{1}\end{array}$ \\
\hline Q1 & -0.90 & 0.15 & 0.60 & 1215.8 & 1042.3 \\
\hline Q2 & 1.16 & 1.04 & 1.63 & 4585.2 & 6544.1 \\
\hline Q3 & 2.07 & 1.90 & 1.20 & 8987.3 & 16444.1 \\
\hline Q4 & 3.33 & 3.28 & 2.24 & 6221.5 & 15090.3 \\
\hline Average & 1.41 & 1.59 & 1.42 & 5252.4 & 9780.2 \\
\hline Number of Countries & 72 & & & & \\
\hline
\end{tabular}

${ }^{1}$ Real GDP per capita, constant US\$; source: World Development Indicators WB

${ }^{2}$ Source: International Financial Statistics IMF

In this paper we test for the existence of wealth effects in the contribution of financial intermediaries development to economic growth. It is important that the study of wealth effects on this relationship separates the effect of financial intermediation from other country and country-group characteristics that may have an asymmetric effect on growth for different income groups. We include country specific effects and a set of control variables that can mitigate this problem. However, the growth promoting effects of financial intermediation cannot be separated from the increase of financial vulnerability that financial development brings about, because financial crises can generate large and persistent output losses. One of the most common proxies for financial intermediation development in the growth literature: "domestic credit to the private sector", is also among the best predictors for banking crises (e.g., Demirguc-Kunt and Degatriache, 1998 and 2000; Kaminsky and Reinhart, 1999). Loayza and Ranciere (2002) using a pooled mean group estimator show that a long-run positive relationship between financial intermediation and growth can coexist with a negative short-run relationship due to financial crises. ${ }^{2}$ Although, in this paper we do not attempt a further exploration of the growth effects of financial crises, the study of wealth effects requires to control for financial crises since banking crises are more frequent in middle income economies (see Gaytan and Ranciere 2003).

We use a GMM dynamic panel data system estimator, as in Levine et. al. (2000), for a sample of 83 countries for the period 1960-2000. This estimation technique addresses the issue of joint endogeneity of financial development, and the other explanatory variables, by using "internal" instruments (lagged values of the explanatory variables). After controlling for the episodes and duration of financial crises, we analyze how the level of income per capita modifies the estimated effect of financial intermediation on growth performance. We use two standard measures to proxy

\footnotetext{
${ }^{2}$ Gaytan and Ranciere (2003) provide a theoretical model to integrate the short-run analysis of financial crises and the long-run positive contribution of financial intermediation on economic growth.
} 
financial intermediaries development: liquid liabilities to GDP, and domestic credit to the private sector to GDP. For both indicator the results of the estimations show the existence of wealth effects, and suggest that in economies with low levels of income, financial development has a consistently lower growth effect and for some low levels of wealth, this effects can even be negative; in addition, at some middle-high level of income the positive contribution to growth is maximum, and then it starts to decrease. ${ }^{3}$

On the theoretical side, it has been recognized that financial intermediaries play several roles that can foster economic growth. Among these roles, financial intermediaries: ( $i$ ) provide an efficient mechanism that channels investment to its higher returns; (ii) are efficient suppliers of liquidity, can transform illiquid assets into liquid liabilities; (iii) provide liquidity insurance that reduces idiosyncratic liquidity risk; (iv) allow an efficient pooling of risk among different investment projects; $(v)$ ameliorate information asymmetries, are efficient institutions for screening and monitoring investment projects. ${ }^{4}$ The model developed in this paper, to account for the observed wealth effects, focuses only on the relationship between the first three roles, stated above, and economic growth.

We use an intertemporal model of financial intermediaries to analyze the dynamics of wealth, capital and consumption. The models embeds a modified version of the Diamond and Dybvig (1983) model of liquidity provision (DD henceforth) into an overlapping generations framework. ${ }^{5}$ There are two technologies available: a storage technology, and a long term technology. The long term technology is characterized by a Cobb Douglas production function with capital and labor as inputs. This technology constitutes the channel of investment and growth over time and among generations.

\footnotetext{
${ }^{3}$ Odedokun (1996) finds that the positive effect of financial development on growth is higher for low income than for high income LDCs, an opposite result than the one presented here. However, this author estimates time series equations, one per each country using OLS-GLS with potential biases due to the endogeneity of explanatory variables (including factor accumulations rates), and it does not take into account potential country specific effects, and the higher recurrence of financial crises episodes in high income LDCs.

${ }^{4}$ See for example Greenwood and Jovanovic (1990), Saint Paul (1992), Acemoglu and Zilibotti (1997). Levine (1997) presents an excelent review of the growth promoting effects of financial intermediation in the literature.

${ }^{5}$ Since in this paper we are interested in the long run effect of financial intermediation on growth, and in the empirical estimation we have control for the effect of banking crises, in the theoretical model of this paper we abstract from financial crises. In Gaytan and Ranciere (2003) we present a model that includes the possibility of the bank run equilibrium, and show what are the growth and welfare consequences of having financial crises with positive probability
} 
As a benchmark of zero financial development, we study financial autarky, where agents have no access to credit markets. This benchmark is useful to study the effect on output, consumption and welfare of introducing financial intermediaries. Financial intermediaries provide liquidity insurance to maximize welfare of the current generation of depositors. However this insurance may introduce costs in terms of economic growth. For low levels of wealth, the provision of liquidity insurance may force an early liquidation of long term projects that, although efficient in terms of welfare of the current generation, may reduce the rate of capital accumulation. Nevertheless, once the economy crosses certain threshold of economic development, this trade off disappears, and, financial intermediaries can provide liquidity insurance and attain higher levels of growth and output. In this case, the role of banks as liquidity providers is always growth enhancing. However, at some high level of wealth, once the economy has exhausted the consumption risk sharing possibilities, and it is no longer optimal to increase growth promoting investments.

Bencivenga and Smith (1991), Ennis and Keister (2003), Qi (1994) and Fulghieri and Rovelli (1998) have studied the DD model in overlapping generations frameworks. Qi (1994) and Fulghieri and Rovelli (1998) focus is on intergenerational transfers and not on growth; their models have technologies with constant returns to capital and are endowment economies without capital accumulation or any wealth dynamics. Ennis and Keister (2003) and Bencivenga and Smith (1991) are closer to our paper, they investigate the relationship between financial intermediation and growth. However, their models are endogenous growth models with constant returns to capital, with this assumption, the effect of financial intermediation is no longer wealth dependent. In our model, the use of a Cobb-Douglas technology for the long asset makes the returns to investment endogenous, and the banking solution -its investment portfolio, liquidation policy and payoffs to depositorsdependent on wealth of the economy, and introduces the possibility of a trade off between short run liquidity and economic growth.

The rest of the paper is organized as follows. Section 2 presents the data, methodology and the estimation results of wealth effects in the financial intermediation-growth relationship. Section 3 presents the general set up of the model: the structure of overlapping generations, preferences and the technologies available. Section 4 presents the portfolio choice and the growth implications of financial autarky. Section 5 presents the optimal risk sharing solution of financial intermediation and its consequences for economic growth. Section 6 analyzes the consequences of financial intermediation in terms of welfare and growth. Finally, section 7 concludes. 


\section{Wealth Effects in Financial Intermediation-Growth Re- lationship}

In this section we study how the exogenous component of financial intermediation affects economic growth for different levels of income per capita. For this purpose we use the methodology of GMM dynamic panel data system estimator developed in Arellano and Bond (1991), Arellano and Bover (1995) and Blundell and Bond (1998). ${ }^{6}$ This methodology addresses the issues of joint endogeneity of all explanatory variables in a dynamic formulation, and of potential biases induced by country specific effects. First, we describe the methodology and data used in the estimation, and then we show that the estimation results support the existence of wealth effects in the contribution of financial development to economic growth.

\subsection{Data and Methodology}

The data set consists of a panel of observations for 83 countries for the period 1960-2000. To smooth the series from the business cycle fluctuations, and concentrate on long run growth effects of financial intermediation, we use low frequency data by averaging, for each country, the information on growth and the explanatory variables in at most 8 non-overlapping five-year periods. The resulting panel of country and time-period observations is unbalanced. Table 2 in Appendix B presents the lists of countries included in the sample.

The dependent variable is average income per capita growth. We use two indicators of financial development: liquid liabilities as a proportion of GDP, and domestic credit to the private sector to GDP. Liquid liabilities is a standard measure of financial depth, it measures the size of the financial sector. Private credit goes beyond a size effect of financial intermediation, it provides more information on the level of financial services and the growth promoting activities of financial intermediaries. In addition to the financial development variables, the regressions include a set of control variables. Initial income per capita is included, as it is standard in the growth literature, to capture either the distance from the steady state, for a Solow-type growth model, or the catching up effect of new technologies, for an endogenous growth model. To control for human capital we use average years of secondary schooling. Inflation and the size of the government (government

\footnotetext{
${ }^{6}$ Applications of this methodology to the growth-financial development relationship are: Levine et. al. (2000) and Beck et. al. (2000).
} 
expenditure as proportion of GDP) enter the regression to control for macroeconomic stability. Finally, the degree of trade openness (exports and imports as proportion of GDP) is presumed to have a positive impact on growth. Table 3 in Appendix B, presents the definitions and sources used in our estimation.

We are interested in estimating the following equation:

$$
y_{i, t}-y_{i, t-1}=(\alpha-1) y_{i, t-1}+\beta^{\prime} C V_{i, t}+\gamma F D_{i, t}+\mu_{t}+\eta_{i}+\varepsilon_{i, t},
$$

where $y$ is the logarithm of real per capita GDP, $C V$ is the set of control variables other than initial income, $F D$ is the financial development measure, $\mu_{t}$ is the time-specific effect, $\eta_{i}$ is the country-specific effect, and $\varepsilon$ is the error term.

As a first approximation, we test for the existence of wealth effects in the relationship between financial intermediation and growth by introducing slope dummies for financial development variables for different income groups. We substitute the financial intermediation part in equation (1) by: $\sum_{j \in J} \gamma^{j} F D_{i, t}^{j}$, where $F D_{i, t}^{j}$ is a slope dummy that takes the value of $F D_{i, t}$ if country $i$ belongs to the income group $j$, and zero otherwise. We use two different classifications; the first set of income groups is defined by the classification of the World Bank for low, middle low, middle high, and high income-OECD countries. The income groups using this classification are $J=\left\{\gamma_{L}, \gamma_{M L}, \gamma_{M H}, \gamma_{O E C D}\right\} .{ }^{7}$ However, the World Bank classification does not necessarily provide the appropriate thresholds for wealth effects on the finance-growth relationship, thus in addition, we use a more flexible classification. We define income groups using deciles for average initial income per capita for the country-data used in the estimation, and the income groups are $J=\left\{\gamma_{1}, \ldots, \gamma_{10}\right\}$. Table 2 in Appendix B presents the list of countries and their respective classifications. ${ }^{8}$

Another way to capture the existence of wealth effects on the relationship is through the use of a non linear specification in which the initial level of income per capita interacts with financial development. As we will see, the estimation results for the decile classification suggest that

\footnotetext{
${ }^{7}$ The groups are classified according with their GNI per capita: low income, $\$ 735$ or less; lower middle income, $\$ 736$ - $\$ 2,935$; upper middle income, $\$ 2,936$ - $\$ 9,075$; and high income, those countries that belong to the OECD and have a GNI greater than $\$ 9,076$, this excludes Mexico and Turkey from the OECD members. With this classification, 29 percent of the countries included in the sample are clasified as low income economies, 29 percent as middle-low, 14 percent as middle-high, and 28 percent as high income.

${ }^{8}$ There is an important drawback with these two classifications: they do not acount for changes over time across income groups. The estimation procedure uses first differences of the explanatory variables, making not valid to allow for variations of income groups.
} 
the contribution of financial development to growth $\gamma$ can be approximated by a linear quadratic specification: $\gamma=\delta_{0}+\delta_{1} y_{i, t-1}+\delta_{2} y_{i, t-1}^{2}$. Thus, equation 1 can be written as:

$$
y_{i, t}-y_{i, t-1}=(\alpha-1) y_{i, t-1}+\beta^{\prime} C V_{i, t}+\delta_{0} F D_{i, t}+\delta_{1} F D_{i, t} y_{i, t-1}+\delta_{2} F D_{i, t} y_{i, t-1}^{2}+\mu_{t}+\eta_{i}+\varepsilon_{i, t} .
$$

This specification has the advantage that does not rely on fixed groups of countries, and ideally it would allow us to identify: (i) whether there is, within the sample, a low threshold of wealth below which the overall contribution of financial development to growth is negative; (ii) the level of wealth at which this contribution starts to decrease, that is, the level at which the marginal effect becomes negative; and (iii) whether there is a within sample large level of wealth above which further financial development is detrimental for growth.

Even if the use of five year averages reduces the potential effects of unaccounted short term fluctuations, the lasting recessions associated with financial crises may still contaminate the financegrowth relationship. Moreover, since the frequency and costs of banking crises are higher for middle income economies, an assessment of wealth effects on the growth contribution of financial development must control for banking crises episodes. Accounting for the effect of banking crises in a low frequency data set presents some conceptual complications. The first complication is that frequently banking crises are preceded by lending booms with high growth and, after the usual recession associated with the crisis, economic growth can be lower than average. In addition, the duration of crises differ for each episode. Within a five year period several combinations are possible. We choose to account for the effects of banking crises on economic growth only for the duration of the crises as reported in Caprio and Klingebiel (1999, 2003). For this purpose we construct a frequency of crises dummy variable that takes the value of the proportion of the five-year period with banking crisis. For example, for the 1977-1983 Israeli banking crises, the dummy variable will take the value of 0.8 in the period 1976-1980, and 0.6 for the period 1981-1985. This dummy variable is then included to control for the output losses generated by the crises. ${ }^{9}$

\section{Methodology}

The estimation of equation (1) poses some challenges. The first, is the presence of time and country specific effects. Time effects can be accounted for by including period-specific dummies, however, the common methods to account for individual effects (within or difference estimators)

\footnotetext{
${ }^{9}$ It is also possible to hypotetize that further financial expansion in a context of financial vulnerability can be detrimental to economic growth, and include an interactive crises-financial development dummy. However this variable is consistently non significant.
} 
are not valid since the resulting error term is correlated with initial income. The second problem is the likely joint endogeneity of most explanatory variables and economic growth. Simultaneous or reverse causation can generate biases in the estimates of the contribution of financial development to growth. In the following paragraphs we outline the econometric methodology used to control for unobserved country-specific effects and joint endogeneity in a dynamic model of panel data.

We use the Generalized-Method-of-Moments (GMM) estimators developed for dynamic models of panel data, introduced by Holtz-Eakin, Newey, and Rosen (1988), Arellano and Bond (1991), and Arellano and Bover (1995). Taking advantage of the panel nature of the data, these estimators are based on, first, differencing regressions and/or instruments to control for unobserved effects, and, second, using lagged observations of the explanatory variables in levels as instruments (called "internal" instruments). After accounting for the time-specific effects and grouping all explanatory variables in a vector $X$, equation (1) can be rewritten as:

$$
y_{i, t}=\alpha y_{i, t-1}+\beta^{\prime} X_{i, t}+\eta_{i}+\varepsilon_{i, t}
$$

In order to eliminate the country-specific effect, we take first-differences of equation (3):

$$
y_{i, t}-y_{i, t-1}=\alpha\left(y_{i, t-1}-y_{i, t-2}\right)+\beta^{\prime}\left(X_{i, t}-X_{i, t-1}\right)+\varepsilon_{i, t}-\varepsilon_{i, t-1} .
$$

The use of instruments must deal with the two challenges of the estimation: (i) the likely endogeneity of the explanatory variables, and (ii) the problem that, by construction, the new error term, $\varepsilon_{i, t}-\varepsilon_{i, t-1}$, is correlated with the lagged dependent variable, $y_{i, t-1}-y_{i, t-2}$. The instruments consist of previous observations of the explanatory and lagged dependent variables. Given that the estimation uses past values of the regressors, the estimation procedure is valid only under the assumption of weak exogeneity of explanatory variables, that is they can be correlated with current and past realizations of the growth rate, but they are assumed to be uncorrelated with future realizations of the error term. ${ }^{10}$

Under the assumptions that (a) the error term, $\varepsilon$, is not serially correlated, and (b) the explanatory variables $X$ are weakly exogenous, the GMM dynamic panel estimator uses the following

\footnotetext{
${ }^{10}$ As Levine et.al. (2000) mention, the assumption of weak exogeneity does not imply that expectations of future growth do not have an effect on current financial development, but only that unanticipated future shocks to economic growth do not influence financial development.
} 
moment conditions:

$$
\begin{aligned}
E\left[y_{i, t-s} \cdot\left(\varepsilon_{i, t}-\varepsilon_{i, t-1}\right)\right] & =0 \text { for } s \geq 2, t=3, \ldots, T, \\
E\left[X_{i, t-s} \cdot\left(\varepsilon_{i, t}-\varepsilon_{i, t-1}\right)\right] & =0 \text { for } s \geq 2, t=3, \ldots, T .
\end{aligned}
$$

The GMM estimator based on these conditions is known as the difference estimator. Although this estimator has clear advantages over the classic difference estimator for panel data it also has some statistical shortcomings. As shown by Alonso-Borrego and Arellano (1999) and Blundell and Bond (1998) when the explanatory variables are persistent over time, the use of lagged levels of these variables make weak instruments for the equations in differences. ${ }^{11}$ In small samples, Monte Carlo experiments show that this weakness can produce biased coefficients. In addition, it influences the consistency of the estimator, because asymptotically the variance of the coefficient estimates rises.

Arellano and Bover (1995) and Blundell and Bond (1997) propose an estimator that reduces potential biases and imprecisions associated with the difference estimator. This new estimator combines in a system the regression in differences with the regression in levels. The instruments for the regression in differences are the same as above. The instruments for the regression in levels are the lagged differences of the corresponding variables. These lagged differences are valid instruments under the additional assumption of no correlation between the change in the explanatory variables and the country-specific effect (which does not rule out the possibility of correlation between the level of these variables and the country-specific effect ). This assumption results from the following mean stationarity property:

$$
E\left(y_{i, t+q} \cdot \eta_{i}\right)=E\left(y_{i, t+p} \cdot \eta_{i}\right) \text { and } E\left(X_{i, t+q} \cdot \eta_{i}\right)=E\left(X_{i, t+p} \cdot \eta_{i}\right) \text { for all } p \text { and } q \text {. }
$$

The additional moment conditions for the second part of the system (the regression in levels) are: ${ }^{12}$ :

$$
\begin{aligned}
E\left[\left(y_{i, t-1}-y_{i, t-2}\right) \cdot\left(\eta_{i}+\varepsilon_{i, t}\right)\right] & =0 \\
E\left[\left(X_{i, t-1}-X_{i, t-2}\right) \cdot\left(\eta_{i}+\varepsilon_{i, t}\right)\right] & =0 .
\end{aligned}
$$

\footnotetext{
${ }^{11}$ The persistence in banking balances make this shortcoming particularly important for the financial intermediation variables.

${ }^{12}$ Given that lagged levels are used as instruments in the differences specification, only the most recent difference is used as instrument in the levels specification. Using other lagged differences would result in redundant moment conditions. (see Arellano and Bover 1995).
} 
Using the moment conditions given by equations (5), (6),(8) and (9), we employ a Generalized Method of Moments (GMM) procedure to generate consistent estimates of the parameters of interest and their asymptotic variance-covariance matrix (Arellano and Bond 1991, and Arellano and Bover 1995). The equations for the system estimator are:

$$
\hat{\theta}=\left(\bar{X}^{\prime} Z \hat{\Omega}^{-1} Z{ }^{\prime} \bar{X}\right)^{-1} \bar{X}^{\prime} Z \hat{\Omega}^{-1} Z^{\prime} \bar{y}
$$

where $\theta$ is the vector of coefficients $(\alpha, \beta), \bar{y}$ is a vector of growth stacked first in differences and then in levels, $\bar{X}$ is a matrix of explanatory variables (including the lagged dependent variable, that is, $\left.\left[y_{t-1}, X\right]\right)$ stacked first in differences and then in levels, $Z$ is the matrix of instruments derived from the moment conditions, and $\hat{\Omega}$ is a consistent estimate of the variance-covariance matrix. ${ }^{13}$

The consistency of the GMM estimators depends on whether lagged values of the explanatory variables are valid instruments in the growth regression. We address this issue by considering two specification tests suggested by Arellano and Bond (1991) and Arellano and Bover (1995). The first is a Sargan test of over-identifying restrictions, which tests the overall validity of the instruments. Failure to reject the null hypothesis gives support to the model. The second test examines the null hypothesis that the error term is not serially correlated. As with the Sargan test, the model specification is supported when the null hypothesis is not rejected. In the system specification we test whether the differenced error term (that is, the residual of the regression in differences) is second-order serially correlated. ${ }^{14}$ Second-order serial correlation of the differenced residual would indicate that the original error term $\varepsilon$ is serially correlated and follows a moving average process at least of order one. This would reject the appropriateness of the proposed instruments (and would call for higher-order lags to be used as instruments).

\footnotetext{
${ }^{13}$ Arellano and Bond (1991) suggest the following two-step procedure to improve the consistency and efficiency of the GMM estimates. The first step: assuming that the residuals $\varepsilon_{i, t}$, are independent and homoskedastic both across countries and over time, it is possible to obtain consistent estimators of the coefficients using an specific weighting matrix to determine the variance covariance matrix $\hat{\Omega}^{-1}$. The residuals obtained from the consistent estimated coefficient of the first step are used to provide a new consistent estimate of the variance-covariance matrix of the moment conditions. This matrix is then used to re-estimate the parameters of interest (i.e. second-step estimates). Asymptotically, the second-step estimates are superior to the first-step ones in so far as efficiency is concerned.

${ }^{14} \mathrm{By}$ construction, first-order serial correlation of the differenced error term is expected even if the original error term $\varepsilon$ is uncorrelated, unless the latter follows a random walk.
} 


\subsection{Estimation Results, Wealth Effects.}

For comparison purposes, Table 4 in Appendix B presents the GMM estimation of the growth equation (1) without accounting for wealth effects. The coefficients of the control variables, with exception of inflation, are significant and have the expected sign. As in previous studies, the results show that financial depth has positive and significant growth effects. Moreover, when we control for the output loss generated by banking crises, there is an important increase in the contribution of financial intermediation to income per capita growth.

Table 5 presents the estimation results with wealth effects using the World Bank classification of countries. Financial development exerts a positive and significant effect on growth for all income groups; the exception is when financial development is proxied using liquid liabilities, in the low income group of countries this contribution is statistically insignificant. Moreover, for both indications of financial depth, there is evidence that low income countries have a smaller benefit of further financial development than middle income and high income countries: when we control for banking crises, this benefit in low income countries is around a third of the effect in the other income groups. In addition, Table 5 contains the results of hypothesis tests to identify whether there are significant differences in the growth effects of financial intermediation for the other income groups. When credit to the private sector is used, we cannot reject that for middle income and high income groups the effect is the same. However, when we use liquid liabilities, high income-OECD economies enjoy a significantly higher growth gains from financial intermediation than middle income countries.

Although the previous estimation provides some evidence of wealth effects in the finance-growth relationship, the income thresholds defined by the World Bank classification are not necessarily the appropriate for this relationship. We group countries in deciles according with their average initial income. Table 6 reports the growth regression results using this classification. These results depict a clearer picture of the existence of wealth effects in the contribution of financial development to economic growth: (i) for the lowest deciles of income per capita, this contribution is negative; (ii) this contribution appears to be increasing in the level of income (except for a drop in the middle of the distribution). Figures 1 and 2 in Appendix B summarize the coefficients of financial development in the growth equation, and their 95 percent confidence interval.

The results of the decile classification suggest that we can approximate the effect of financial intermediation on growth by a linear quadratic interaction between financial development and the initial level of income per capita contained in equation 2; Table 7 presents the results of these 
estimations. The parameters of financial development are highly significant for both indicators of financial depth, and their signs suggest the existence of three thresholds of income per capita: (i) a low level of income, below which financial development is detrimental to income growth $\left(y_{o}^{1}\right)$; (ii) a threshold when the effect is maximum, and further increases in financial depth have a lower contribution to growth $\left(y_{o}^{2}\right)$; and (iii) a high income threshold where the contribution becomes negative $\left(y_{o}^{3}\right)$. Table 7 also reports these three thresholds for both proxies of financial development. The low income threshold $y_{o}^{1}$ for private credit is $\$ 131.2,{ }^{15} 4$ countries have observations below this threshold, for a total of 10 observations (represent only 1.5\% of the sample). For liquid liabilities the threshold $y_{o}^{1}$ is $\$ 167.7$, there are 7 countries with a total of 22 observations (3.3\% of the sample). The second thresholds $y_{o}^{2}$ are $\$ 3,835.6$ for private credit and $\$ 4,711.5$ for liquid liabilities. In the region defined between the first and the second threshold there are 61 countries and 428 observations (64.5\% of the sample) for private credit, and 61 countries and 441 observations (66.4\% of the sample) for liquid liabilities. The third thresholds $y_{o}^{3}$ are well beyond the maximum level of income per capita in the sample $(\$ 112,155.1$ and $\$ 132,382.9$ for private credit and liquid liabilities respectively while the maximum observation is $\$ 45,952$ ). Thus we cannot give any meaning to the level $y_{o}^{3}$. In the region defined by income per capita above $y_{o}^{2}$, there are 226 observations ( $34 \%$ of the sample) of 33 countries for private credit, and 201 observations (30.3\% of sample) of 28 countries.

In all the different especifications used, the Sargan tests and the second order correlation tests indicate that we cannot reject the validity of the moment conditions assumed for the estimation.

In the rest of the paper we develop a model of financial intermediation to offer an explanation of the wealth effects observed in the estimation.

\section{The Basic Model}

The economy consists of an infinite sequence of overlapping generations. In each period, a generation, composed by a continuum of ex-ante identical agents with unit mass, is born; there is no population growth.

Agents live for two periods. They have an endowment of one unit of labor during the first period of their lives, which they supply inelastically. Agents do not value consumption when they are young. During the second period of their life they are subject to a time preference shock. With

\footnotetext{
${ }^{15}$ Purchasing power parity 1995 international dollars.
} 
probability $\pi$, an agent only values consumption when middle aged (the beginning of her second period), and becomes an early consumer. With probability $(1-\pi)$, she only values consumption when old (the end of her second period) and becomes a late consumer. The shock is stochastically independent across agents, and is private information to the agent. Preferences of an agent that belongs to generation $t$ are:

$$
\begin{aligned}
& U\left(c_{t}^{t}, c_{E}^{t}, c_{L}^{t}\right)=\theta u\left(c_{E}^{t}\right)+(1-\theta) u\left(c_{L}^{t}\right) \\
& \text { with: }\left\{\begin{array}{ccc}
\theta=1 & \text { with probability } & \pi \\
\theta=0 & \text { with probability }(1-\pi)
\end{array}\right. \text {, and } \\
& u(c)=\frac{c^{1-\sigma}}{1-\sigma}
\end{aligned}
$$

where $c_{E}^{t}, c_{L}^{t} \geq 0$, are the levels of early and late consumption at $t+1$ of an agent born at $t$.

There is one good, used for consumption and investment. There are two technologies available. A storage technology, that uses the good as unique input and, for each unit invested at $t$, gives a return of one unit in any sub-period of $t+1$. There is also a long term technology with a CobbDouglas production function, which uses labor $l$ and capital $k$ as inputs. Capital fully depreciates after being used in production. If the technology is left until full maturity (the end of the period), it gives the return: $\digamma(k, l)=A k^{\beta} l^{1-\beta}$. Since the unit of labor is supplied inelastically, the capital intensive production function can be defined as:

$$
f(k) \equiv \digamma(k, 1)=A k^{\beta}
$$

This production can be prematurely liquidated, with a liquidation cost. In this case, the product generated is a fraction $0<\gamma<1$ of the full return at maturity $\gamma f(k)$. Hence, this liquidation cost is expressed in terms of output and not in terms of capital. ${ }^{16}$

Factor markets are competitive, and each input is paid its realized marginal product. However, the realized marginal product depends on the financial arrangements in the economy because it depends on the proportion of long term projects liquidated.

Wages received at the end of period $t$ represent the unique source of wealth for members of the generation. After receiving wages, agents realize their investment decisions before observing the

\footnotetext{
${ }^{16}$ This assumption makes the relative marginal returns of a long project left until maturity and liquidated prematurely a constant $\left(\frac{f^{\prime}(k)}{\gamma f^{\prime}(k)} \equiv \frac{1}{\gamma}\right)$.
} 
realization of their liquidity shock. ${ }^{17}$ There is an initial generation endowed with $w_{0}>0$ units of the consumption good.

\section{Financial Autarky}

In this section we develop the benchmark solution of financial autarky. This benchmark will be used to analyze the growth and welfare costs and benefits of financial intermediation.

Under financial autarky, young agents make their investment decision between storing goods and investing in capital by their own. We assume that each worker supplies her unit of labor to a continuum of representative firms with mass $m \in(0,1] .{ }^{18}$. With this assumption, young workers are paid a wage equal to the expected marginal product of labor $w_{t+1}=(1-\beta)[\pi \gamma+1-\pi] f\left(k_{t}\right)$ and, at the same time, the investors (old agents) receive the marginal product of their investmentliquidation decision $(\gamma \beta f(k)$ if early consumer and $\beta f(k)$ if late).

\subsection{The Optimal Individual Investment Decision}

We start by analyzing the investment problem of a representative member of an arbitrary generation, and show her optimal portfolio decision as a function of her level of wealth $(w)$.

Define the return of holding the long asset as the function $h(k) \equiv \beta f(k)$. The marginal return of the long investment is $h^{\prime}(k)$ if the investment is maintained until full maturity, and $\gamma h^{\prime}(k)$ if it is liquidated prematurely. Let's define the two following capital levels:

$$
\begin{aligned}
\underline{k} \text { such that } \gamma h^{\prime}(\underline{k}) & =1 \\
\bar{k} \text { such that } h^{\prime}(\bar{k}) & =1
\end{aligned}
$$

Since labor is inelastically supplied, the long term asset presents diminishing returns to capital. For low levels of capital $(k<\underline{k})$, the marginal return of the long term asset, even when it is

\footnotetext{
${ }^{17}$ We abstract from the consumption-saving decision to stress the choice among assets with different liquidity. Agents do not value consumption when young, the consumption-saving decision at $t$ is trivial, and they will invest their full wealth either directly in the two technologies (autarky), or as bank deposits (financial intermediation).

${ }^{18}$ This mass $m$ can be arbitrarily close to zero, however, it is equivalent to assume that every worker works for all firms. This assumption is not essential for the results of the paper, and it helps to avoid heterogeneity in the size of firms, that would unnecessarily complicate the dynamics of the model.
} 
prematurely liquidated, exceeds the marginal return of the storage technology $\left(\gamma h^{\prime}(k) \geq 1\right)$. Beyond some level of investment in the long asset $(k>\bar{k})$, its marginal return is lower than one $\left(h^{\prime}(k) \leq 1\right)$.

Under financial autarky, investment in capital is risky because its return depends on the realization of the liquidity shock. At the end of their first period, for any given level of wealth $w>0$, a typical agent of generation $t$, chooses investment in the long technology $k$ to maximize:

$$
\begin{gathered}
\pi u\left(c_{E}\right)+(1-\pi) u\left(c_{L}\right) \\
\text { subject to } 0 \leq k \leq w
\end{gathered}
$$

where $c_{E}=w-k+\gamma h(k), c_{L}=w-k+h(k)$, and the difference between wealth and capital $(w-k)$ is investment in the storage technology.

The following proposition characterizes the optimal solution for members of any given generation under financial autarky.

Proposition 4.1 For every level of wealth $w$, the unique solution $\left(k_{\text {opt }}(w), c_{E}(w), c_{L}(w)\right)$ to the agent's problem under autarky is characterized by the following conditions:

There exists a unique level of wealth $w^{*} \in(\underline{k}, \bar{k})$ defined by $\frac{u^{\prime}\left(\gamma h\left(w^{*}\right)\right)}{u^{\prime}\left(h\left(w^{*}\right)\right)}=\frac{(1-\pi)\left(h^{\prime}\left(w^{*}\right)-1\right)}{\pi\left(1-\gamma h^{\prime}\left(w^{*}\right)\right)}$ such that:

$$
\begin{aligned}
& \text { (i) if } w \leq w^{*} \text { then }\left\{\begin{array}{c}
k_{o p t}(w)=w \\
c_{E}=\gamma h(w) \quad \text { (corner solution) } \\
c_{L}=h(w)
\end{array}\right. \\
& \text { (ii) if } w>w^{*} \text { then }\left\{\begin{array}{c}
0<k_{o p t}(w)<w \\
c_{E}=w-k_{o p t}+\gamma h\left(k_{o p t}\right) \quad \text { (interior solution) } \\
c_{L}=w-k_{o p t}+h\left(k_{o p t}\right)
\end{array}\right.
\end{aligned}
$$

where $k_{\text {opt }}(w)$ in $(i i)$ is defined by: $\frac{u^{\prime}\left(c_{E}\right)}{u^{\prime}\left(c_{L}\right)}=\frac{(1-\pi)\left(h^{\prime}\left(k_{o p t}\right)-1\right)}{\pi\left(1-\gamma h^{\prime}\left(k_{o p t}\right)\right)}$

\section{Proof. See Appendix A.}

The intuition for this result is the following: the expected marginal benefit of investing in capital is $(1-\pi) u^{\prime}\left(c_{L}\right)\left(h^{\prime}(k)-1\right)$, while the expected marginal cost is $\pi u^{\prime}\left(c_{E}\right)\left(1-\gamma h^{\prime}(k)\right)$. For low levels of wealth it is possible that $\gamma h^{\prime}(w)>1$, the marginal cost of investing all wealth in capital is negative, while the marginal benefit is large. The threshold $w^{*}$ is defined as the level of wealth at which full investment in capital equates marginal benefit and marginal cost. This threshold defines 
two regions of the optimal portfolio under financial autarky. When wealth is lower than $w^{*}$, agents invest their full wealth in capital; above this threshold they invest in both assets ${ }^{19}$. The optimal capital choice $k_{\text {opt }}(w)$ is strictly increasing and concave in $w$. The proportion of wealth invested in the long asset, $\frac{k_{\text {opt }}(w)}{w}$ is constant for $w \leq w^{*}$, and it is strictly decreasing in $w$ for $w>w^{* 20}$.

Investment under autarky is inefficient. The first inefficiency arises because in poor economies, self insured agents invest, as precautionary savings, their full wealth in capital beyond the point where it is efficient to do so. When the marginal return of the short asset exceeds the marginal liquidation value of the long asset, $\left(\gamma h^{\prime}(w)<1\right)$, it would be efficient to start investing in the short asset. However, $w^{*}>\underline{k}$ means that for levels of wealth between $\underline{k}$ and $w^{*}$ agents are over-investing in the long asset $(k=w)$. The second inefficiency occurs for levels of wealth greater than $w^{*}$. Early consumers are forced to liquidate productive investments to cover their liquidity needs, while late consumers finance some of their consumption using the less productive liquid investment. The impossibility of receiving insurance through financial markets generates an inefficient liquidation of the long investment. ${ }^{21}$ This liquidation implies that capital is bounded above by $k_{\max }\left(h^{\prime}\left(k_{\max }\right)=\right.$ $\left.\frac{1}{\pi \gamma+(1-\pi)}>1\right)$, while it is efficient to invest up to the higher level $\bar{k}\left(h^{\prime}(\bar{k})=1\right) .^{22}$

For low levels of wealth, when agents are investing only in the long technology, liquidity self insurance is constant $\left(\frac{c_{E}}{c_{L}}=\gamma\right)$. For higher levels of wealth, when agents are investing in both assets $\left(w>w^{*}\right)$, an increase in wealth reduces the gap between early and late consumption. Nevertheless, full liquidity risk insurance is not possible under financial autarky.

\subsection{The Dynamics of Wealth, Capital and Consumption Under Au- tarky}

In this part, we characterize the steady state of the economy and study the evolution of wealth, capital and consumption towards this stationary equilibrium. Since capital fully depreciates after it is used, the connection between the individual problem and the dynamics of the intertemporal model is given by wages of the next generation.

\footnotetext{
${ }^{19}$ The threshold level of wealth $w^{*}$ is defined by: $h^{\prime}\left(w^{*}\right)=\frac{\pi+(1-\pi) \gamma^{\sigma}}{\gamma \pi+(1-\pi) \gamma^{\sigma}}$

${ }^{20}$ See appendix A for the derivation of the properties of the optimal capital choice function

${ }^{21}$ This is the inefficiency of autarky that in DD motivates a role for banks as efficient liquidity providers.

${ }^{22} \mathrm{~A}$ risk neutral consumer will invest in a risky asset up to the point where the actuarial marginal return of the risky asset equates the marginal return of the safe asset; a risk averse consumer will invest always strictly less than this level and $\lim _{w \rightarrow \infty} k_{\text {opt }}(w)=k_{\max }$
} 
At $t=1$ an initial old generation exists, endowed with $w_{0}>0$, and we assume that this wealth has already been invested according with the optimal conditions stated in proposition 4.1 . The timing convention is that a generation born at $t$ makes its optimal choice of capital $k_{t+1}$, therefore:

$$
\begin{aligned}
w_{t} & =F^{a}\left(w_{t-1}\right)=(1-\beta)(\pi \gamma+1-\pi) f\left(k\left(w_{t-1}\right)\right) \\
k_{t} & =k\left(w_{t-1}\right)=k_{\text {opt }}\left(w_{t-1}\right)
\end{aligned}
$$

Since $f(\cdot), k(\cdot)$ are continuous, increasing and concave, and $k_{\text {opt }}(0)=0$ and $\lim _{w \rightarrow \infty} k_{\text {opt }}(w)=k_{\max }$, $F^{a}(w)$ is a continuous, increasing and concave function. Moreover, $F^{a}(w)=w$ admits a unique stable non zero root. For any positive initial wealth $w_{0}>0$, this implies the following dynamics:

Proposition 4.2 Convergence and the steady state under financial autarky.

(i) The economy converges monotonically and asymptotically towards a unique stable steady state $\bar{w}^{a}>0$ and $k\left(\bar{w}^{a}\right)$.

(ii) The steady state has investment in both assets $\left(\bar{w}^{a}>w^{*}\right)$ if and only if $\frac{1-\beta}{\beta^{2}} \frac{f^{\prime}\left(w^{*}\right)}{f^{\prime}\left(k_{\max }\right)}>1 .{ }^{23}$

Proof. See Appendix A.

Figure 4 in Appendix $\mathrm{C}$ presents the dynamics of wealth. ${ }^{24}$ It shows how the economy converges to its stationary equilibrium $\bar{w}^{a}$. Beyond the threshold $w^{*}$, the rate of growth decreases rapidly, overinvestment in the previous region has already exhausted the marginal returns on capital, and the constant level of liquidation $\pi$ becomes more and more costly in terms of growth. Finally, as both consumptions $\left(c_{E}, c_{L}\right)$ are monotonically increasing in wealth, their dynamics follow the dynamics of wealth.

\section{Intra-generational Risk-Sharing and Financial Interme- diaries.}

Uncertainty in this economy pertains to the liquidity needs of individuals and is idiosyncratic. Therefore, welfare gains are possible via a mechanism of liquidity preference insurance. Diamond and Dybvig (1983) show that, in the absence of banking crises, the first best solution can be

\footnotetext{
${ }^{23}$ The position of the steady state between the two regions, defined by $w^{*}$, gives a qualitative characterization of the steady state but does not determine its level, because the threshold $w^{*}$ is a function of the parameters.

${ }^{24}$ The parameters used in the simulation are presented in Appendix C.
} 
implemented through a competitive banking system with standard deposit contracts. Nevertheless, if banks offer the first best contract, the first best equilibrium is one of two possible equilibria. In the second equilibrium there is a coordination of beliefs that banks will not be able to service all the deposits at the late sub-period, driving a total run on the bank at the beginning of $t+1$. In this paper we abstract from these run equilibrium, and assume that banks can offer the optimal risk sharing. In Gaytan and Ranciere (2004) we explore the consequences of having bank runs with positive probability.

\subsection{Generation's $t$ Optimal Risk-Sharing}

In this model, a financial intermediary is a mutual, in which members of the same generation pool their resources. After having worked in the first period, agents deposit their full wealth $w$ in the bank. On the aggregate, all uncertainty disappears: by the law of large numbers, the bank knows that a proportion $\pi$ of agents will demand their deposits in the early sub-period, and a proportion $(1-\pi)$ in the late sub-period. Therefore, the bank can select the investment portfolio $(k)$, the optimal proportion of the long asset that it will liquidate prematurely $(\lambda)$, as well as the fixed payoffs for early and late consumers to form the most efficient match between liquidity needs of agents and the highest returns of the assets. In addition, the bank centralizes production and pays a wage to the following generation $\left(w^{\prime}\right)$ equal to the realized marginal product of labor $w^{\prime}=(1-\beta)(\lambda \gamma+1-\lambda) f(k)$.

At any period $t$, and for any given level of deposits (wealth $w>0$ ), a representative bank chooses $k, \lambda, c_{E}$ and $c_{L}$ to maximize expected utility of a representative current depositor:

$$
\begin{aligned}
\pi & u\left(c_{E}\right)+(1-\pi) u\left(c_{L}\right) \text { subject to } \\
0 & \leq k \leq w \\
0 & \leq \lambda \leq 1 \\
\pi c_{E} & \leq w-k+\lambda \gamma h(k) \\
\pi c_{E}+(1-\pi) c_{L} & \leq(1-\lambda) h(k)+w-k+\lambda \gamma h(k) \\
c_{E} & \leq c_{L}
\end{aligned}
$$

Equation 20 is the resource constraint at the early sub-period of $t+1$; for serving agents with early liquidity needs, the bank can liquidate the short asset $(w-k)$ and a proportion $\lambda$ of the long term 
technology. Equation 21 is the resource constraint at the late sub-period of $t+1$; the bank uses all its remaining assets to service late consumers. Agents still have access to the storage technology, therefore, the bank must offer a higher return to patient consumers so that they do not withdraw their funds at the early stage and store it up to the late stage. This is reflected in the incentive compatibility constraint (22).

The bank provides the optimal level of liquidity (given by the liquidation policy of the long asset $(\lambda)$ and investment in the short technology $(w-k))$ and by the provision of optimal liquidity insurance $\left(\frac{c_{E}}{c_{L}}\right)$. Liquidity provision can be measured by the share of liquidity requirements of early consumers covered using the short asset $\left(\frac{w-k}{\pi c_{E}}\right)$.

The complete characterization of the optimal solution of the problem is stated in the following proposition (see Appendix A for proofs and details).

Proposition 5.1 For each level of wealth the unique solution $\left(k_{\text {opt }}(w), \lambda_{\text {opt }}(w), c_{E}(w), c_{L}(w)\right)$ to the optimal risk sharing problem is characterized by the following conditions:

\begin{tabular}{|c|c|c|c|c|c|c|}
\hline & $w$ & F.O.C & $k_{o p t}$ & $\lambda_{o p t}$ & $c_{E}$ & $c_{L}$ \\
\hline $\mathbf{A}$ & $0<w \leq \underline{k}$ & $\frac{u^{\prime}\left(c_{E}\right)}{u^{\prime}\left(c_{L}\right)}=\frac{1}{\gamma}$ & $w$ & $\lambda^{*}$ constant & $\frac{\lambda^{*} \gamma h(w)}{\pi}$ & $\frac{\left(1-\lambda^{*}\right) h(w)}{1-\pi}$ \\
\hline B & $\underline{k} \leq w \leq \widetilde{w}$ & $\begin{array}{l}\frac{u^{\prime}\left(c_{E}\right)}{u^{\prime}\left(c_{L}\right)}=\frac{1}{\gamma} \\
\gamma h^{\prime}(k)=1\end{array}$ & $\underline{k}$ & $0 \leq \lambda(w) \leq \lambda^{*}$ & $\frac{w-\underline{k}+\lambda \gamma h(\underline{k})}{\pi}$ & $\frac{(1-\lambda) h(\underline{k})}{1-\pi}$ \\
\hline $\mathrm{C}$ & $\widetilde{w} \leq w \leq \hat{w}$ & $\begin{array}{l}\frac{u^{\prime}\left(c_{E}\right)}{u^{\prime}\left(c_{L}\right)}=h^{\prime}(k) \\
1<h^{\prime}(k)<\frac{1}{\gamma}\end{array}$ & $\underline{k}<k_{\text {opt }}<\bar{k}$ & $\lambda=0$ & $\frac{w-k_{o p t}}{\pi}$ & $\frac{h\left(k_{o p t}\right)}{1-\pi}$ \\
\hline D & $w \geq \hat{w}$ & $\frac{u^{\prime}\left(c_{E}\right)}{u^{\prime}\left(c_{L}\right)}=1$ & $\overline{\bar{k}}$ & $\lambda=0$ & $w-\bar{k}+h(\bar{k})$ & $=c_{E}$ \\
\hline
\end{tabular}

where $\underline{k}$ and $\bar{k}$ were defined in section $3.1 ; \widetilde{w}, \hat{w}, \lambda^{*}$ and $\lambda_{\text {opt }}(w)$ are defined by:

$$
\begin{aligned}
\widetilde{w} & =\underline{k}\left(1+\frac{\pi \gamma^{1 / \sigma}}{(1-\pi) \gamma \beta}\right) \\
\hat{w} & =\bar{k}\left(1+\frac{\pi}{\beta(1-\pi)}\right) \\
\lambda^{*} & =\frac{\pi \gamma^{\frac{1}{\sigma}}}{\pi \gamma^{\frac{1}{\sigma}}+(1-\pi) \gamma} \\
\lambda(w) & =\lambda^{*}-\left(1-\lambda^{*}\right) \beta \frac{w-\underline{k}}{\underline{k}}
\end{aligned}
$$

The optimal portfolio and liquidation policy define four regions (A to $\mathbf{D}$ ) delimited by the income thresholds $\underline{k}, \tilde{w}$ and $\hat{w}$ : 


\section{Region A: No investment in short-term technology, no liquidity provision and con- stant level of liquidity insurance.}

Region A is defined as the range of wealth $(w \leq \underline{k})$ for which investing in capital dominates investment in the short asset. The optimal portfolio is the same than under autarky, all wealth is invested in the long term asset. In this case, the bank is not providing extra liquidity, but only acting as a liquidity insurance provider. The bank is liquidating prematurely a fixed proportion of the long technology $\lambda^{*}$. Optimal liquidation increases with the degree of risk aversion, which reflect agents' preference for liquidity insurance. For sufficiently high risk aversion $(\sigma>1)$, optimal liquidation is higher than aggregate liquidation under autarky $\pi$. In that case, higher liquidity insurance imposes the cost of lower output, and rate of growth than under autarky.

Region B: Constant level of long-term investment, reduction of early liquidation, increasing liquidity provision and constant level of liquidity insurance

For $\underline{k} \leq w \leq \widetilde{w}$ the financial intermediary invests in both assets and provides extra liquidity. Investment in capital is kept fixed at $\underline{k}$, the bank keeps the marginal return of the long asset fixed at a high level, so that its marginal return, when liquidated prematurely, equals the marginal return of storing the good..$^{25}$ Even if the capital stock is fixed, output can grow because the bank is liquidating a decreasing proportion of the long asset, that is reflected as an increase in total factor productivity. The bank starts using the liquid asset as a source of liquidity to pay out early consumers, reducing premature liquidation of the long asset. Late consumers are served using an increasing proportion of the fully matured output. However, since the bank is still using premature liquidation to serve early agents, liquidity insurance is kept fixed at the same level as in region A.

Region C: No liquidation of long term investment, increasing investment in both assets, constant provision of liquidity and increasing level of liquidity insurance.

When wealth has crossed certain threshold $(w \geq \widetilde{w})$, the financial intermediary stops using the long asset to serve early consumers. All the long technology is left until full maturity $(\lambda=0)$ to serve late consumers, and investment in capital can increase again. Increasing investment in capital over this region implies that the marginal return of the asset used to serve late consumers decreases relative to the marginal return of the asset used for early consumption, making optimal to increase liquidity insurance $\left(\frac{u^{\prime}\left(c_{E}\right)}{u^{\prime}\left(c_{L}\right)}=h^{\prime}(k)\right.$ implies that $\frac{c_{E}}{c_{L}}$ is increasing in $\left.w\right) .{ }^{26}$

\footnotetext{
${ }^{25}$ Two assets can be used to serve the same type of consumption only if their marginal returns are the same at the required moment of liquidation.

${ }^{26}$ The faster the increase in capital, the faster is the improvement in liquidity insurance.
} 


\section{Region D: Full insurance, provision of liquidity for late consumers.}

For high levels of wealth $(w>\hat{w})$ investment in the long asset is kept fixed at the level $(\bar{k})$ at which the marginal return of both assets is equalized $\left(h^{\prime}(\bar{k})=1\right)$, and it is optimal for the bank to provide perfect insurance by offering the same level of consumption for early and late withdrawers. ${ }^{27}$ Early consumption is always served using the storage technology, yet, when wealth is strictly greater than the threshold $\hat{w}$, late consumption is served using both assets and implies a transfer of the liquid asset to the late subperiod.

The regions of the optimal risk sharing solution imply that liquidity and liquidity insurance provided by the bank are endogenous, and they increase with the level of deposits (wealth) received in each period. A larger economy will have higher liquidity, less inefficient liquidation, and better insurance among different liquidity needs. In the following section we analyze the dynamics of this economy.

\subsection{The Dynamics of Wealth, Capital and Consumption}

Financial intermediaries can implement welfare superior allocations for consumers of any given generation, in this section we analyze the dynamic implications of this financial arrangement. We show that the economy has a unique stationary equilibrium $\left(\bar{w}^{b}\right)$ and analyze the dynamics of wealth, capital and consumption.

At any period, wages $w_{t}$, capital $k_{t}$ and optimal liquidation $\lambda_{t}$ are defined by the following relations:

$$
\begin{aligned}
& w_{t}=F^{b}\left(w_{t-1}\right)=(1-\beta)\left(\lambda\left(w_{t-1}\right) \gamma+1-\lambda\left(w_{t-1}\right)\right) f\left(k\left(w_{t-1}\right)\right) \\
& k_{t}=k_{\text {opt }}\left(w_{t-1}\right) \\
& \lambda_{t}=\lambda_{\text {opt }}\left(w_{t-1}\right)
\end{aligned}
$$

The properties of $F^{b}\left(w_{t-1}\right)$ (see Appendix A) imply the following properties of the dynamics of wealth.

Proposition 5.2 Convergence and the steady state under financial intermediation.

\footnotetext{
${ }^{27}$ Perfect insurance is possible because there are decreasing returns to capital. When the returns to capital are constant, the provision of perfect insurance require some form of intergenerational transfer, see Fulgueri and Rovelli (1998).
} 
(i) For any initial wealth $w_{0}>0$, the economy with financial intermediaries has a unique, stable steady state $\bar{w}^{b}>0$ and $k^{s s}=k\left(\bar{w}^{b}\right)$. The steady state is defined by $F^{b}\left(\bar{w}^{b}\right)=\bar{w}^{b}{ }^{28}$

(ii) For any positive level of initial wealth $w_{0}>0, w_{0} \neq \bar{w}^{b}$, the economy converges monotonically towards its steady state $\bar{w}^{b}$ :

- if $\bar{w}^{b}<\hat{w}$ this convergence is asymptotic.

- if $\bar{w}^{b}>\hat{w}$ the economy converges to the steady state in finite time.

\section{Proof. See Appendix A}

The dynamics of early and late consumption under financial intermediation follow the dynamics of wealth. When wealth is increasing (decreasing) over time, both types of consumption are increasing (decreasing). In regions A,B, and D, keeping liquidity insurance constant implies that both early and late consumptions must be growing at the same rate. By contrast, in Region C, liquidity insurance is increasing in capital $\frac{c_{E}}{c_{L}}=\left(\frac{1}{h^{\prime}(k(w))}\right)^{\frac{1}{\sigma}}$. Thus, if wealth is growing over region $\mathrm{C}$, the rate of growth of early consumption must be greater than the rate of growth of late consumption. Positive growth over this region implies improving insurance.

\section{The Consequences of Financial Intermediation.}

In this section, we analyze the implications of the presence of financial intermediaries by comparing the consequences, for welfare and economic growth, of the autarkic and banking solutions (the variables of these solutions are indexed by $\{a, b\}$ respectively).

The fundamental source of inefficiency under financial autarky is the absence of a mechanism for pooling liquidity risk, making necessary that each agent insures herself against such risk. Since the bank can implement optimal risk sharing among current depositors, for a given level of wealth, welfare for the current generation is necessarily higher than under financial autarky.

Under banking, liquidation of the long technology is optimally chosen and it allows to distribute a fraction of the high returns of this asset to early consumers. Once the economy has attained certain level of wealth, it gradually reduces this liquidation to zero. Conversely under autarky, aggregate liquidation of the long term technology remains a constant fraction $\pi$. Since the marginal

\footnotetext{
${ }^{28}$ The position of the steady state among the different regions, as in autarky, does not determine its level.
} 
products of capital and labor depend inversely on the level of liquidation, its suppression is central to explain why financial intermediaries can attain a higher steady state level of wealth.

The following proposition compares the optimal capital choice under financial autarky and financial intermediation.

Proposition 6.1 It exists a unique wealth level $m \in\left(\max \left\{w^{*}, \widetilde{w}\right\}, \widehat{w}\right)$, such that the optimal capital choice under financial intermediation and the optimal choice under autarky are equal for $w=m$. For $\underline{k}<w<m$, the capital choice is higher under autarky that under financial intermediation (overinvestment). For $w>m$, the capital choice is lower under autarky that under financial intermediation (underinvestment)

\section{Proof. see Appendix A}

Figure 3 compares the optimal capital choice and liquidation policy of both regimes for each level of wealth. In autarky, over-investment for low levels of wealth is a direct consequence of precautionary saving behavior of agents that face idiosyncratic liquidity risk. At low levels of wealth $w \in\left(\underline{k}, w^{*}\right)$, agents overinvest in the long asset when it would be efficient to start investing a fraction of wealth in the short asset and reduce liquidation. In region $\mathrm{B}, w \in(\underline{k}, \widetilde{w})$, the marginal return of capital under financial autarky decreases, whereas, under financial intermediation it increases because capital is kept fixed and liquidation is reduced. Consequently, investment under financial intermediation increases faster in Region $\mathrm{C}\left(w \in\left[\underline{k}, w^{*}\right]\right)$. Even when both economies invest the same level of capital $(w=m)$, growth and the marginal returns of factors are higher for financial intermediation since there is no costly liquidation. After this point, aggregate underinvestment in capital is a direct consequence of the low marginal return to capital due to inefficient liquidation. ${ }^{29}$

We now compare the dynamics of wealth under financial autarky and financial intermediation. We focus on the dynamics of wealth rather than on the dynamics of capital, because wealth reflects both the optimal capital choice and the optimal liquidation policy of the previous generation. For any level of wealth $w$, it is possible to decompose the growth consequences of the financial regimes using the ratio of output of the long term technologies.

$$
\frac{F^{a}(w)}{F^{b}(w)}=\frac{1-\pi(1-\gamma)}{1-\lambda(w)(1-\gamma)}\left(\frac{k^{a}(w)}{k^{b}(w)}\right)^{\beta}
$$

\footnotetext{
${ }^{29}$ Notice that our analysis of the inefficiency of financial autarky echoes the literature on precautionary savings in presence of uninsured idiosyncratic risks and liquidity constraints (Aiyagari (1994), Jappelli and Pagano (1994), Calvet-Angeletos (2001)).
} 
Which can be written in terms of growth rates as:

$$
g^{a}(w)-g^{b}(w) \approx \underbrace{\ln (1-\pi(1-\gamma))-\ln (1-\lambda(w)(1-\gamma))}_{\text {Liquidation Effect }(\mathrm{A})}+\beta \underbrace{\left[\ln k^{a}(w)-\ln k^{b}(w)\right]}_{\text {Investment Effect (B) }}
$$

The relative growth performance depends on the combination of a liquidation effect (A), that reflects the different level of liquidation $(\lambda(w)$ vs. $\pi)$, and an investment effect $(\mathrm{B})$, that reflects the difference in capital choice. In terms of growth accounting, the first effect expresses a "total factor productivity" gap and the second effect an investment gap. On the one hand, autarkic agents are over-investing in capital on $(\underline{k}, m)$; nevertheless, this investment effect vanishes gradually and it changes sign afterwards (see Fig 4a). On the other hand, the liquidation effect will eventually favor the economy with financial intermediaries as they reduce liquidation to zero (at $\widetilde{w})$. The strength and timing of these effects will crucially depend on the level of risk aversion of agents.

For $w \leq \underline{k}$, investment is identical in both regimes, and any difference in growth must come from differences in liquidation. For high risk aversion $(\sigma>1)$, financial intermediaries provide high liquidity insurance through higher liquidation than autarky $\left(\lambda^{*}>\pi\right)$, and as a consequence the economy exhibits lower growth. By contrast, when agents are less risk averse $(\sigma<1)$, the liquidation level is lower under financial intermediation $\left(\lambda^{*}<\pi\right)$, allowing a higher growth rate than autarky.

For $\underline{k}<w<m$, there is a sufficiently low level of risk aversion $(\sigma<\underline{\sigma}<1)$ below which lower liquidation by banks completely offsets the effect of autarkic precautionary savings, and the economy with financial intermediaries grows faster. For higher risk aversion, there will always be a range of wealth for which overinvestment in the autarkic economy, as precautionary savings, will translate into a higher growth performance.

For $w \geq m$, growth under financial intermediation is unambiguously higher, as investment is higher and no liquidation is optimal. The comparison in growth performance is summarized in the following proposition:

Proposition 6.2 it exists a $\underline{\sigma} \in(0,1)$

i) For high risk aversion $(\sigma>1)$, there exists a unique level of wealth $w_{u} \in(\underline{k}, m)$ such that for $w>w_{u}\left(w<w_{u}\right)$, the growth rate under financial intermediation is higher (lower) than the growth rate under autarky. 
ii) For low risk aversion $(0<\sigma<\underline{\sigma})$, the growth rate under financial intermediation is strictly higher than the growth rate under autarky.

iii) For intermediate risk aversion $(\underline{\sigma} \leq \sigma \leq 1)$, the growth rate under financial intermediation is higher than under financial autarky for $w \in \Re-\left[w_{L}, w_{u}\right]$ with $\left[w_{L}, w_{u}\right] \subset[\underline{k}, m)$

\section{Proof. see Appendix A}

Figure 4 in Appendix Cpresents a comparison of the dynamics under both financial arrangements for a simulation of the economy (with $\sigma=2$ ). From any level of wealth $w_{t-1}$, we can read the transitional dynamics towards the steady states $\left(\bar{w}^{a}=F^{a}\left(\bar{w}^{a}\right)\right.$ and $\left.\bar{w}^{b}=F^{b}\left(\bar{w}^{b}\right)\right)$. This graph illustrates the growth cost of liquidity insurance: at early stage of economic development, the economy with financial intermediaries has a lower rate of growth. After the economy has crossed the threshold $w_{u}$ financial intermediation has a strictly growth enhancing effect. Figure 4 also illustrates the stage at which the development of a banking system starts to have crucial long run effects. When the economy has enough resources to keep an increasing number of long term projects until full maturity, financial intermediation has an increasing contribution to growth. This result replicates the empirical importance of financial intermediation for the growth perspectives of middle income or emerging economies, and can explain why they are willing to undertake the risk of increasing financial vulnerability by developing their financial systems (see Gaytan and Ranciere, 2003). For very rich economies $w>\widehat{w}$, financial intermediation implements full liquidity insurance, which is obviously unattainable under financial autarky.

The mapping between the empirical results of Section 2 and the predictions of the theoretical model require some warnings. In the first place, the model compares two extreme regimes: financial autarky and full financial intermediation. In reality, every country is located at some intermediate point between these regimes. In addition, the model concentrates only in the liquidity functions of financial intermediaries, while financial intermediaries perform several other growth promoting activities. Nevertheless, the model can account for the observed wealth effects in the financial intermediation-growth relationship. Figure 5, summarizes the growth contribution of financial development in the model, by taking the difference between growth under financial intermediation and growth under autarky. Financial development has a negative effect on economic growth for low income economies because the optimal intragenerational level of liquidity conflicts with output maturity of productive investments. Middle income countries enjoy higher growth rates, higher 
liquidity insurance, and at some point higher growth than financial autarky. However, when the economy attains complete liquidity insurance, it is no longer optimal to increase investment in growth promoting technologies, and the positive contribution of financial intermediation declines.

\section{Conclusion}

The central empirical finding of the paper is that the effect of financial development on growth depends in a non linear way on the level of income of countries. This effect varies from negative in low-income countries to positive above a certain wealth threshold; it reaches a maximum among middle-income countries before declining for richer countries. This result is robust to the inclusion of fixed effects and to the control for the growth costs associated with banking crises episodes.

We provide a theoretical explanation for this finding that relies on the growth consequences of the liquidity risk-sharing provided by financial intermediaries at different level of income in a neo-classical context. When countries are poor and returns to long term projects high, even when liquidated, banks perform risk-sharing among agents by increasing the share of long term projects. Risk-sharing implies then lower growth. This result is similar to the growth depressing effect of a reduction in precautionary saving in models with incomplete markets (e.g. Ayagari (2000)). When countries becomes richer and returns are lower, it becomes optimal for banks to increase risksharing by using liquid investments to finance early consumption needs. Then risk-sharing implies lower liquidation, higher long term investment and higher growth. In growth accounting terms, the reduction of liquidation corresponds to an increase in total factor productivity that result from bank's efficient match between the liquidity needs and preferences of agents and the timing of the highest returns of the technologies.

Because financial autarky is also equivalent to a monopolistic banking system and financial intermediation to a fully competitive banking system, our results provide elements in the debate on the optimal timing of domestic financial liberalization. In particular, poor economies could benefit to wait before fully liberalizing their banking sectors. 


\section{References}

[1] Acemoglu, D. and Zilibotti, F. (1997), "Was Prometheus Unbound by Chance? Risk, Diversification, and Growth", Journal of Political Economy, 105, 709-751.

[2] Aiyagari S.,"Uninsured Idiosyncratic Risk and Aggregate Saving", 1994,Quarterly Journal of Economics, 109(3), 659-684

[3] Allen, F. and Gale, D. (1998),"Optimal Financial Crises," Journal of Finance 53, 1245-1284.

[4] Allen, F. and Gale, D. (2000), "Optimal Currency Crises", Journal of Monetary Economics, Carnegie-Rochester Conference on Public Policy, forthcoming.

[5] Alonso-Borrego C. and M. Arellano (1999), "Symmetrically Normalized Instrumental-Variable Estimation Using Panel Data", Journal of Business \& Economic Statistics, 17, 36-49.

[6] Angeletos G. and L. Calvet (2001),"Incomplete Markets, Growth and the Business Cycle",unpublished

[7] Arellano M. and O. Bover (1995), "Another Look at the Instrumental-Variable Estimation of Error-Components Models," Journal of Econometrics, 68, 29-51.

[8] Arellano M. and S. Bond (1991), "Some Tests of Specification for Panel Data: Monte Carlo Evidence and an Application to Employment Equations," Review of Economic Studies, 58, $277-297$.

[9] Beck, T., R. Levine, and N. Loayza (2000), "Financial Development and the Sources of Growth," Journal of Financial Economics, 58 (1-2), 261-300.

[10] Bencivenga, V. and Smith, B.(1991),"Financial Intermediation and Endogenous Growth", Review of Economic Studies,58,195-209

[11] Benhabib, J and M Spiegel (2000), "Cross Country Growth Regressions: Are Primitives All That Matter?" Journal of Economic Growth 5, 341-360.

[12] Bhattacharya, S; P. Fulghieri and R. Rovelli (1998), "Financial Intermediation versus Stock Markets in a Dynamic Intertermporal Model", Journal of Institutional and Theoretical Economics, March. 
[13] Blundell R, and S. Bond (1998), "Initial conditions and Moment Conditions in Dynamic Panel Data Models," Journal of Econometrics, 87, 115-143.

[14] Caprio G. and D. Klingbiel, (1999,2003), "Episodes of Systemic and Borderline Financial Crises," mimeo World Bank

[15] Chang, R. and A. Velasco (2000), "Financial Fragility and the Exchange Rate Regime" Journal of Economic Theory; 92(1), 1-34.

[16] Cooper R. and T. Ross (1998),"Bank Runs: Liquidity Costs and Investment Distortions"Journal-of-Monetary-Economics; 41(1), pages 27-38..

[17] De Gregorio J. and P. Guidotti (1995), "Financial Development and Economic Growth," World Development, 23(3), 433-448.

[18] Demirguc A. and G. Degatriache (1998), "The Determinants of Banking Crises in Developing and Developed Countries", IMF Staff-Papers 45 (1), 81-109.

[19] Demirguc A. and G. Degatriache (2000), "Banking Sector Fragility: A Multivariate Logit Approach", World Bank Economic Review, 14 (2), 287-307.

[20] Diamond, D. and Dybvig, P.(1983), "Bank Runs, Deposit Insurance, and Liquidity", Journal of Political Economy, 91, 401-419.

[21] Diamond, P.(1965), "National Debt in a Neoclassical Growth Model", American Economic Review, 55, 1126-1150.

[22] Ennis, H and T Keister (2003), "Economic Growth, Liquidity, and Bank Runs", Journal of Economic Theory 109,. 220-245.

[23] Fulghieri, P. and Rovelli, R, (1998), "Capital markets, financial intermediaries and liquidity supply" Journal of Banking and Finance, 22, 1157-1179.

[24] Gaytan A. and R. Ranciere (2003), "Banks Liquidity Crises and Economic Growth", mimeo NYU.

[25] Gourinchas P.O., O. Landerretche, and R. Valdes, 1999, "Lending Booms: Some Stylized Facts", unpublished. 
[26] Greenwood, J. and Jovanovic, B.(1990), "Financial Development, Growth, and the Distribution of Income", Journal of Political Economy,98,1076-1107

[27] Holtz-Eakin, D., W. Neweyand H. Rosen (1988), "Estimating Vector Autoregressions with Panel Data," Econometrica, Vol. 56 (6), 1371-95.

[28] Japelli T. and M.Pagano (1994), "Saving, Growth and Liquidity Constraints",Quarterly Journal of Economics, 109(1), 83-109

[29] Kaminsky G. and C Reinhart (1999),"The Twin Crises: The Causes of Banking and Balance of Payments Problems,", American Economic Review, Vol. 89, No. 3, 473-500.

[30] King R. and R. Levine (1993a), "Finance and Growth: Schumpeter Might Be Right," Quarterly Journal of Economics, 153(3), 717-38.

[31] King, R. and Levine, R. (1993b). "Finance, entrepreneurship, and growth: Theory and evidence", Journal of Monetary Economics 32, 513-542.

[32] Levine, R. (1997), "Financial Development and Growth: Views and Agenda", Journal of Economic Literature, Vol. 35, No 2, 688-726.

[33] Levine, R. and S. Zervos (1996), "Stock Market Development and Long-Run Growth," World Bank Economic Review, 10.

[34] Levine, R, N. Loayza and T. Beck (2000), "Financial Intermediation and Growth: Causality and Causes," Journal of Monetary Economics, 46(1), 31-77.

[35] Loayza, N and R. Ranciere (2002), "Financial Development, Financial Fragility and Growth", CREDPR, paper No. 164.

[36] Odedokun, M.O. (1996), "Alternative econometric approaches for analyzing the role of the financial sector in economic growth: Time-series evidence from LDCs", Journal of Development Economics, Vol. 50, 119-146.

[37] Patillo, Catherine, Helene Poirson and Luca Ricci. (2002). "External Debt and Growth". IMF W.P. 69, April 2002.

[38] Qi, J. (1994), "Bank liquidity and stability in an overlapping generations model", Review of Financial Studies, 7, 389-417. 


\section{Appendix}

\section{A The Model}

\section{A.1 Financial Autarky}

\section{Proof of proposition 4.1 (The autarkic solution).}

Let's define the value function : $V(k, w)=\pi u(w-k+\gamma h(k))+(1-\pi) u(w-k+h(k))$.

The optimal program is to find $k_{\text {opt }}$ that maximizes $V(k, w)$ subject to $k \leq w$ (since $\lim _{k \rightarrow 0} h^{\prime}(k)=\infty$, $\left.k_{\text {opt }}>0\right) . V(k, w)$ is twice continuous differentiable in $k$ and strictly concave:

$$
\frac{\delta^{2} V(k, w)}{\delta k^{2}}=\left\{\begin{array}{c}
\pi\left(u^{\prime \prime}\left(c_{E}\right)\left(\gamma h^{\prime}(k)-1\right)^{2}+u^{\prime}\left(c_{E}\right) \gamma h^{\prime \prime}(k)\right) \\
+(1-\pi)\left(u^{\prime \prime}\left(c_{L}\right)\left(h^{\prime}(k)-1\right)^{2}+u^{\prime}\left(c_{L}\right) h^{\prime \prime}(k)\right)
\end{array}\right\}<0
$$

We are maximizing a continuous strictly concave function over a compact set $[0, w]$, a maximum $k_{\text {opt }}$ exists and is unique. Define $A(k, w)=\frac{\delta V(k, w)}{\delta k}$ and $\mu$, the Lagrange multiplier associated with $k \leq w$.

(i) First Order Conditions: $A(k, w)=\frac{\delta V(k, w)}{\delta k}=\mu ;\left\{\begin{array}{l}\text { if } k<w \text { (interior solution) } A(k, w)=0 \\ \text { if } k=w \text { (corner solution), } A(k, w)>0\end{array}\right.$

(ii) $\frac{\delta A(k, w)}{\delta k}=\frac{\delta^{2} V(k, w)}{\delta k^{2}}<0$ and $k \leq w \Leftrightarrow A(k, w) \geq A(w, w)$ (with strict inequality if $k<w$ ).

(iii) $\frac{\delta A(w, w)}{\delta w}<0$, hence $A(w, w)=0$ admits a unique solution $w=w^{*}$ defined by $\frac{u^{\prime}\left(\gamma h\left(w^{*}\right)\right)}{u^{\prime}\left(h\left(w^{*}\right)\right)}=$ $\frac{(1-\pi)\left(h^{\prime}\left(w^{*}\right)-1\right)}{\pi\left(1-\gamma h^{\prime}\left(w^{*}\right)\right)}$.

Hence by (i),(ii) and (iii):

(interior and corner solution): for $w=w^{*}: A\left(w^{*}, w^{*}\right)=0$ and $k_{o p t}=w^{*}$.

(corner solution): for $w<w^{*}: A(w, w)>0$ and $k_{\text {opt }}=w$.

(interior solution): for $w>w^{*}: A\left(k_{o p t}, w\right)=0>A(w, w)$ and $k_{\text {opt }}<w$

$$
A\left(k_{\text {opt }}, w\right)=0 \Leftrightarrow \frac{u^{\prime}\left(c_{E}\right)}{u^{\prime}\left(c_{L}\right)}=\frac{(1-\pi)\left(h^{\prime}(k)-1\right)}{\pi\left(1-\gamma h^{\prime}(k)\right)}
$$

and the threshold $w^{*}$ is defined by $h^{\prime}\left(w^{*}\right)=\frac{(1-\pi) \gamma^{\sigma}+\pi}{(1-\pi) \gamma^{\sigma}+\pi \gamma}$

\section{Properties of the optimal capital choice function $k_{\text {opt }}(w)$}

For $w \leq w^{*}, k_{\text {opt }}(w)=w$, and the properties for $w \leq w^{*}$ are obvious. 
For $w \geq w^{*}, k_{o p t}$ is uniquely defined by $A\left(k_{\text {opt }}, w\right)=0$

P1: $k_{\text {opt }}(w)$ is continuous on $\left[w^{*}, \infty\right)$, differentiable in $w$ on $\left[0, w^{*}\right) \cup\left(w^{*}, \infty\right)$ and right and left differentiable at $w^{*} . A(k, w)$ is continuously differentiable in $k$ and $w$.

P2: $k_{\text {opt }}(w)$ is strictly increasing in $w$

$$
\begin{gathered}
\text { for } w \geq w^{*}: \frac{\delta k_{o p t}(w)}{\delta w}=-\left.\frac{\frac{\delta A(k, w)}{\delta(w}}{\frac{\delta(k, w)}{\delta k}}\right|_{A(k, w)=0} \\
\frac{\delta A(k, w)}{\delta k}<0 \text { by }(A 1) \\
\frac{\delta A(k, w)}{\delta w}>0 \Leftrightarrow \frac{u^{\prime \prime}\left(c_{L}\right)}{u^{\prime \prime}\left(c_{E}\right)}<\frac{u^{\prime}\left(c_{L}\right)}{u^{\prime}\left(c_{E}\right)} \Leftrightarrow c_{L}>c_{E}
\end{gathered}
$$

P3: $k_{\text {opt }}(w)$ is concave in $w$ and strictly concave for $w \geq w^{*}$.

P4: $\frac{k_{\text {opt }}(w)}{w}$ is non increasing in $w$, and strictly decreasing for $w \geq w^{*}$

$$
\text { for } w \geq w^{*}: \frac{\delta^{2} k_{o p t}(w)}{\delta w^{2}}=\left.\frac{\partial\left(-\frac{\frac{\delta A(k, w)}{\delta w}}{\delta A(k, w)}\right)}{\partial w}\right|_{A(k, w)=0}
$$

Using (A3) and the properties of the utility function, (A4) can be rewritten as:

$$
\frac{\delta k_{o p t}(w)}{\delta w}=\frac{-\sigma\left(c_{L}-c_{E}\right)}{\frac{c_{E} c_{L}(1-\gamma) h^{\prime \prime}(k)}{\left(1-\gamma h^{\prime}(k)\right)\left(h^{\prime}(k)-1\right)}-\sigma\left[c_{L}\left(1-\gamma h^{\prime}(k)\right)+c_{E}\left(h^{\prime}(k)-1\right)\right]}=\frac{-\sigma\left(c_{L}-c_{E}\right)}{D}
$$

hence,

$$
\frac{\delta^{2} k_{o p t}(w)}{\delta w^{2}}=\frac{\sigma\left(c_{L}-c_{E}\right)\left[\frac{\left(c_{E}+c_{L}\right)(1-\gamma) h^{\prime \prime}(k)}{\left(1-\gamma h^{\prime}(k)\right)\left(h^{\prime}(k)-1\right)}-\sigma(1-\gamma) h^{\prime}(k)\right]}{\mathrm{D}^{2}}<0
$$

At $w=w^{*}, k_{o p t}^{(-)}\left(w^{*}\right)=1$, while $k_{o p t}^{(+)}\left(w^{*}\right)=\frac{\sigma}{\sigma+\frac{\gamma(1-\beta) h\left(w^{*} h^{\prime}\left(w^{*}\right)\right.}{w^{*}\left(1-\gamma h^{\prime}(k)\right)\left(h^{\prime}(k)-1\right)}}<1$

P6 $k_{\text {opt }}(w)$ is bounded by $k_{\max }=h^{\prime-1}\left(\frac{1}{1-\pi+\pi \gamma}\right)$. By construction $c_{L}>c_{E} \Leftrightarrow \frac{u^{\prime}\left(c_{E}\right)}{u^{\prime}\left(c_{L}\right)}<1 \Leftrightarrow k_{\text {opt }}<$ $h^{\prime-1}\left(\frac{1}{1-\pi+\pi \gamma}\right)=k_{\max }$ by $(\mathrm{A} 3)$.hence as $w \rightarrow \infty, c_{E} \rightarrow c_{L}$ and $\frac{u^{\prime}\left(c_{E}\right)}{u^{\prime}\left(c_{L}\right)} \rightarrow 1 \Leftrightarrow h^{\prime}(k) \rightarrow \frac{1}{1-\pi+\pi \gamma}$.

\section{Proof of proposition 4.2 (Steady state and convergence under autarky).}

Define the growth rate of wealth $g\left(w_{t-1}\right)=\frac{F^{a}\left(w_{t-1}\right)}{w_{t-1}}$.

(i) The growth rate of wealth is decreasing. $1+g\left(w_{t-1}\right)=\frac{1-\beta}{\beta}(\pi \gamma+1-\pi) f^{\prime}\left(k\left(w_{t-1}\right)\right) \frac{k\left(w_{t-1}\right)}{w_{t-1}} \cdot \frac{k\left(w_{t-1}\right)}{w_{t-1}}$ is non increasing, $k\left(w_{t-1}\right)$ is strictly increasing, hence $f^{\prime}\left(k\left(w_{t-1}\right)\right.$ is strictly decreasing. $\lim _{w \rightarrow \infty} \frac{k\left(w_{t-1}\right)}{w_{t-1}}=0$ and $\lim _{w \rightarrow \infty} f^{\prime}\left(k\left(w_{t-1}\right)\right)=f^{\prime}\left(k_{\max }\right)$, then $\lim _{w \rightarrow \infty} 1+g\left(w_{t-1}\right)=0$.

Using l'Hopital Rule, $\lim _{w \rightarrow 0} \frac{f\left(k\left(w_{t-1}\right)\right)}{w_{t-1}}=\lim _{w \rightarrow 0} f^{\prime}\left(k\left(w_{t-1}\right)\right)=\infty$. 
(ii) The steady state (uniqueness, stability and convergence).

From (i), $\exists ! \bar{w}^{a}$ such that $g\left(\bar{w}^{a}\right)=0 \Leftrightarrow F^{a}\left(\bar{w}^{a}\right)=\bar{w}^{a}$ has a unique non zero root.

Since by definition $g\left(\bar{w}^{a}\right)=0$ and $g(\cdot)$ is strictly decreasing $\Rightarrow \forall w_{t-1}<\bar{w}^{a}, g\left(w_{t-1}\right)>0$ and $\forall w_{t-1}<\bar{w}^{a}, g\left(w_{t-1}\right)>0$. Then, the unique steady state is stable.

Since $F^{a}\left(w_{t-1}\right)$ is strictly increasing: $w_{1}>w_{0} \Longrightarrow F\left(w_{1}\right)>F\left(w_{0}\right) \Leftrightarrow w_{2}>w_{1} \Leftrightarrow w_{t}>w_{t-1}, \forall t \geq 0$ (by iteration), thus, convergence is asymptotic.

\section{A.2 Optimal Risk Sharing and Financial Intermediation}

Remark A.1 We are maximizing a continuous function over a compact set, then a maximum exists.

Proof. of proposition 5.1 (The optimal risk sharing solution).

The maximization problem (eqns. 17-22) can be simplified before solving: (a) $k_{\text {opt }}>0$ since $h^{\prime}(0)=\infty$; (b) $\lambda<1$, if $\lambda=1$ it would always be possible to increase both $c_{E}$ and $c_{L}$ by reducing liquidation of the long technology; (c) following Allen and Gale (1998), we solve the problem without the ICC (eqn 22), and then show that the optimal solution always satisfies it. The problem becomes Choose $k, \lambda, c_{L}, c_{E}$ to Maximize $\pi u\left(c_{E}\right)+(1-\pi) u\left(c_{L}\right)$ s.t.: (i) $\lambda \geq 0$; (ii) $k \leq w\left(\mu_{1}\right)$; (iii) $\pi c_{E} \leq w-k+\lambda \gamma h(k)\left(\mu_{2}\right)$; and (iv) $\pi c_{E}+(1-\pi) c_{L} \leq(1-\lambda) h(k)+w-k+\lambda \gamma h(k)\left(\mu_{3}\right)$.

First Order Conditions. Based on the Kuhn-Tucker conditions:

$$
\begin{gathered}
u^{\prime}\left(c_{E}\right)=\mu_{2}+\mu_{3} \\
u^{\prime}\left(c_{L}\right)=\mu_{3} \\
\left(\mu_{2}+\mu_{3}\right) \gamma \leq \mu_{3} \text { with equality if } \lambda>0 \\
\left(\mu_{2}+\mu_{3}\right)\left(1-\lambda \gamma h^{\prime}(k)\right)+\mu_{1}=\mu_{3}(1-\lambda) h^{\prime}(k)
\end{gathered}
$$

(C) The incentive-compatibility constraint is satisfied by the optimal solution:(A9) and (A10) $\Rightarrow$ $u^{\prime}\left(c_{E}\right)=\mu_{2}+u^{\prime}\left(c_{L}\right), \quad \mu_{2} \geq 0 \Rightarrow c_{E} \leq c_{L}$

\section{The optimal solution.}

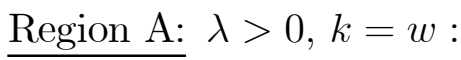

$$
\begin{gathered}
\lambda>0 \Rightarrow \frac{u^{\prime}\left(c_{E}\right)}{u^{\prime}\left(c_{L}\right)}=\frac{1}{\gamma} \\
\mu_{1} \geq 0 \text { and }(\mathrm{A} 13) \Rightarrow \gamma h^{\prime}(w) \geq 1 \Rightarrow \text { case } \mathbf{A} \text { applies for }: w \in[0, \underline{k}]
\end{gathered}
$$




$$
\begin{gathered}
c_{E}=\frac{\lambda \gamma h(w)}{\pi} \text { and } c_{L}=\frac{(1-\lambda) h(w)}{(1-\pi)} \\
(A 15) \text { in }(A 13) \Rightarrow \lambda_{o p t}=\lambda^{*} \equiv \frac{\pi \gamma^{1 / \sigma}}{\pi \gamma^{1 / \sigma}+(1-\pi) \gamma}
\end{gathered}
$$

optimal liquidation in this region is constant. Notice that: $\lambda^{*} \underset{<}{\gtrless} \pi \Leftrightarrow \sigma \underset{<}{\gtrless} 1$.

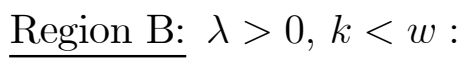

$$
\lambda>0, k<w \Rightarrow \frac{u^{\prime}\left(c_{E}\right)}{u^{\prime}\left(c_{L}\right)}=\frac{1}{\gamma}=\frac{(1-\lambda) h^{\prime}(k)}{1-\lambda \gamma h^{\prime}(k)}
$$

implies a constant optimal choice of capital: $\gamma h^{\prime}(k)=1 \Leftrightarrow k_{o p t}=\underline{k}$, and $c_{E}=\frac{w-\underline{k}+\lambda \gamma h(\underline{k})}{\pi}$ and $c_{L}=$ $\frac{(1-\lambda) h(\underline{k})}{(1-\pi)}$. Optimal liquidation policy is obtained by substituting the two consumptions in (A13):

$$
\begin{gathered}
\lambda_{\text {opt }}(w)=\lambda^{*}-\left(1-\lambda^{*}\right) \beta \frac{w-\underline{k}}{\underline{k}} \\
\lambda(w) \geq 0 \Leftrightarrow w \leq \tilde{w}=\underline{k}\left(1+\frac{\pi \gamma^{\frac{1}{\sigma}}}{(1-\pi) \gamma \beta}\right) \Rightarrow \text { case } \mathbf{B} \text { applies for }: w \in[\underline{k}, \tilde{w}]
\end{gathered}
$$

$\underline{\text { Region } \mathrm{C}:} \lambda=0, k<w$ and $(i i i)$ binding:

$$
\begin{gathered}
\lambda=0, k<w \Rightarrow \frac{u^{\prime}\left(c_{E}\right)}{u^{\prime}\left(c_{L}\right)}=h^{\prime}(k) \leq \frac{1}{\gamma} \\
\Rightarrow k \geq \underline{k} \text { and } h^{\prime}(k) \geq 1 \Rightarrow k \leq \bar{k} \\
h^{\prime}(k) \rightarrow 1 \Rightarrow w \rightarrow \hat{w}=\bar{k}\left(1+\frac{\pi}{\beta(1-\pi)}\right) \Rightarrow \text { case } \mathbf{C} \text { applies for }: w \in[\tilde{w}, \hat{w}] \\
k_{\text {opt }} \in[\underline{k}, \bar{k}] \quad \text { is defined by }: \frac{u^{\prime}\left(\frac{w-k_{o p t}}{\pi}\right)}{u^{\prime}\left(\frac{h\left(k_{o p t}\right)}{1-\pi}\right)}=h^{\prime}\left(k_{\text {opt }}\right)
\end{gathered}
$$

Over region $\mathrm{C}$ the optimal capital choice is unique $\left(\left.\frac{d A(k, w)}{d k}\right|_{\tilde{w} \leq w \leq \hat{w}}<0\right)$ :

$$
\begin{aligned}
A(k, w) & =u^{\prime}\left(\frac{h(k)}{1-\pi}\right) h^{\prime}(k)-u^{\prime}\left(\frac{w-k}{\pi}\right)=0 \Leftrightarrow k=k_{\text {opt }} \\
\frac{d A(k, w)}{d k} & =u^{\prime}\left(c_{L}\right) h^{\prime \prime}(k)+u^{\prime \prime}\left(c_{L}\right) \frac{h^{\prime \prime}(k)^{2}}{1-\pi}+u^{\prime \prime}\left(c_{E}\right) \frac{1}{\pi}<0
\end{aligned}
$$

$\underline{\text { Region } \mathrm{D}:} \lambda=0, k<w$ and $(i i i)$ not binding:

$$
\lambda=0, k<w \Rightarrow \frac{u^{\prime}\left(c_{E}\right)}{u^{\prime}\left(c_{L}\right)}=h^{\prime}(k)
$$




$$
\text { (iii) not binding } \Rightarrow c_{E}=c_{L}=c \Leftrightarrow h^{\prime}(k)=1 \Leftrightarrow k_{o p t}=\bar{k}
$$

and optimal consumption is: $c=w-\bar{k}+h(\bar{k})$.

\section{Properties of the optimal policy function $k_{\text {opt }}(w)$.}

The properties of optimal investment in capital are trivial for regions $\mathrm{A}, \mathrm{B}$ and $\mathrm{D}(w \in$ $\left.\Re^{+} /[\widetilde{w}, \hat{w}]\right)$, where $k_{\text {opt }}(w)$ is either equal to $w$, or constant and equal to $\underline{k}$ or $\bar{k}$. Thus, we focus on region C. For $w \in\left[\widetilde{w}, w^{*}\right]$ :

PC1 $k_{\text {opt }}(w)$ is strictly increasing. $k_{\text {opt }}(w)$ is implicitly defined by: $A(k, w)=h^{\prime}(k) u^{\prime}\left(\frac{h(k)}{1-\pi}\right)-$ $u^{\prime}\left(\frac{w-k}{\pi}\right)=0 . A(k, w)$ is a continuous, decreasing differentiable function in $k$. Using the IFT:

$$
\left.k_{\text {opt }}^{\prime}(w)\right|_{\tilde{w} \leq w \leq \hat{w}}=\frac{\sigma k}{\sigma k+(w-k)(1-\beta+\sigma \beta)}>0
$$

$\mathrm{PC} 2 k_{\text {opt }}(w)$ is strictly concave in $w$ for $w \in[\widetilde{w}, \hat{w}]$

$$
\left.k_{o p t}^{\prime \prime}(w)\right|_{\tilde{w} \leq w \leq \hat{w}}=\frac{-\sigma k(1-\beta+\sigma \beta)}{[\sigma k+(w-k)(1-\beta+\sigma \beta)]^{2}}<0
$$

\section{Dynamics with financial intermediaries.}

Concavity of $F^{b}(w)$.

The following properties of $F^{b}\left(w_{t-1}\right)$ follow directly from the properties of $f\left(w_{t-1}\right), k\left(w_{t-1}\right)$ and $\lambda\left(w_{t-1}\right)$. The function $F^{b}\left(w_{t-1}\right)$ :

(i) is continuous on $[0, \infty)$.

(ii) is strictly increasing on $[0, \hat{w}]$ and constant on $[\hat{w}, \infty)$

(iii) is differentiable on $[0, \underline{k}) \cup(\underline{k}, \widetilde{w}) \cup(\widetilde{w}, \hat{w}) \cup(\hat{w}, \infty)$, left and right differentiable at $k, \widetilde{w}, \hat{w}$. As we shown below:

$F^{b}\left(w_{t-1}\right)$ is strictly concave on $[0, \widetilde{w}]$, strictly concave on $[\widetilde{w}, \hat{w}]$, concave on $[\widetilde{w}, \infty) \cdot F^{b}\left(w_{t-1}\right)$ is strictly concave on $[0, \hat{w}]$ and concave on $\Re^{+}$iff $\sigma \leq \frac{1-\beta}{\beta} \frac{1-\gamma}{\gamma} \lambda^{*}$

Proposition A.1 $F^{b}\left(w_{t-1}\right)$ is concave on $[0, \infty)$ if and only if $\sigma \leq \frac{1-\beta}{\beta} \frac{1-\gamma}{\gamma} \lambda^{*}$.

The proof consists in analyzing concavity within the different regions and the slopes of the function $F^{b}\left(w_{t-1}\right)$ at the thresholds $(\underline{k}, \widetilde{w}, \hat{w})$.

Region A: $F^{b \prime}\left(w_{t-1}\right)=(1-\beta)\left(1-\lambda^{*}(1-\gamma)\right) f^{\prime}\left(w_{t-1}\right)>0$, and 
$F^{b \prime \prime}\left(w_{t-1}\right)=(1-\beta)\left(1-\lambda^{*}(1-\gamma)\right) f^{\prime \prime}\left(w_{t-1}\right)<0$. Hence, $F^{b}(\cdot)$ is strictly concave.

At the threshold $\underline{k}$ the slope is $F^{b \prime(-)}(\underline{k})=\frac{1-\beta}{\beta} \frac{\pi \gamma^{\frac{1}{\sigma}}+1-\pi}{\pi \gamma^{\frac{1}{\sigma}}+(1-\pi) \gamma}$

Region B: $F^{b \prime}\left(w_{t-1}\right)=\frac{1-\beta}{\beta} \frac{(1-\gamma)(1-\pi)}{\pi \gamma^{\frac{1}{\sigma}}+(1-\pi) \gamma}($ constant $)$. Then $F^{b \prime(-)}(\underline{k})>F^{b \prime(+)}(\underline{k})$.

Region $\mathrm{C}: F^{b \prime}\left(w_{t-1}\right)=(1-\beta) f^{\prime}\left(w_{t-1}\right) k^{\prime}\left(w_{t-1}\right)>0$ and since $k^{\prime \prime}\left(w_{t-1}\right)<0$

$F^{b \prime \prime}\left(w_{t-1}\right)=(1-\beta)\left(f^{\prime \prime}\left(w_{t-1}\right) k^{\prime}\left(w_{t-1}\right)+f^{\prime}\left(w_{t-1}\right) k^{\prime \prime}\left(w_{t-1}\right)\right)<0$

At $\widetilde{w}: F^{b \prime(+)}(\tilde{w})=\frac{(1-\beta)}{\gamma \beta} \frac{\sigma \underline{k}}{\sigma \underline{k}+(\tilde{w}-\underline{k})(1-\beta+\beta \sigma)}$, and at $\hat{w}: F^{b \prime(-)}(\hat{w})=\frac{(1-\beta)}{\beta} \frac{\sigma \bar{k}}{\sigma \bar{k}+(\hat{w}-\bar{k})(1-\beta+\beta \sigma)}>0$

Then $F^{b \prime(-)}(\widetilde{w}) \geq F^{b \prime(+)}(\widetilde{w}) \Longleftrightarrow \sigma<\frac{1-\beta}{\beta} \frac{1-\gamma}{\gamma} \lambda^{*}$

Region D: $F^{\prime}\left(w_{t-1}\right)=0$

Then $F^{b \prime(-)}(\hat{w})>F^{b \prime(+)}(\hat{w})=0$

If $\sigma>\frac{1-\beta}{\beta} \frac{1-\gamma}{\gamma} \lambda^{*}$ the set defined by the curve $F^{b}\left(w_{t-1}\right)$ is non-convex. However, as we show in the following proof, the steady state equilibrium is unique.

\section{Proof of proposition 5.2 (The steady state and convergence).}

(i) The growth rate of wealth is decreasing (the continuity of $F^{b}(w)$ implies the continuity of $g^{b}(w)$ ). Region A: $1+g^{b}(w)=\frac{1-\beta}{\beta}\left(\lambda^{*} \gamma+1-\lambda^{*}\right) f^{\prime}(w) \Rightarrow \frac{d g^{b}(w)}{w}<0$

Region B: $1+g^{b}(w)=(1-\beta) f(\underline{k})\left\{\left(1+\frac{\pi \gamma^{\frac{1}{\sigma}}+(1-\pi) \beta \gamma}{\pi \gamma^{\frac{1}{\sigma}}+(1-\pi) \gamma}\right) \frac{1}{w}+\frac{(1-\pi)(\gamma \beta)}{\pi \gamma^{\frac{1}{\sigma}}+(1-\pi) \gamma} \frac{1}{\underline{k}}\right\} \Rightarrow \frac{d g^{b}(w)}{w}<0$

Region C: $1+g^{b}(w)=\frac{1-\beta}{\beta} f^{\prime}(k) \frac{k}{w}$, then $g^{\prime}(w)=\frac{1-\beta}{\beta} f^{\prime}(k)\left(\frac{w k^{\prime}(w)-k}{w^{2}}-\frac{(1-\beta) k^{\prime}(w)}{w}\right)$

hence, $g^{\prime}(w)<0 \Longleftrightarrow \beta w k^{\prime}(w)<k \Longleftrightarrow k\left(\frac{\beta \sigma w}{\sigma k+(w-k)(1-\beta+\beta \sigma)}-1\right)<0 \Leftrightarrow \sigma k+(w-k)>0$ which is always satisfied.

Region D: $1+g^{b}(w)=(1-\beta) \frac{f(\bar{k})}{w} \Rightarrow \frac{d g^{b}(w)}{w}<0$. By continuity $g^{b}(w)$ is strictly decreasing.

$\lim _{w_{t-1} \rightarrow \infty} \frac{(1-\beta) f(\bar{k})}{w_{t-1}}=0 \Rightarrow \lim _{w_{t-1} \rightarrow \infty} g^{b}\left(w_{t-1}\right)=-1$

Using l'Hopital rule, $\lim _{w_{t-1} \rightarrow 0} \frac{F^{b}\left(w_{t-1}\right)}{w_{t-1}}=\lim _{w_{t-1} \rightarrow 0} F^{b \prime}\left(w_{t-1}\right)=\infty$ 
(ii) Uniqueness and stability of the steady state.

From (i), $F^{b}\left(\bar{w}^{b}\right)=\bar{w}^{b}$ has a unique root.

Since by definition $g\left(\bar{w}^{b}\right)=0$ and $g(\cdot)$ is continuous and strictly decreasing $\Rightarrow \forall w_{t-1}<\bar{w}^{b}$, $g\left(w_{t-1}\right)<0$ and $\forall w_{t-1}<\bar{w}^{b}, g\left(w_{t-1}\right)>0$. Then, the unique steady state is stable.

(iii) Asymptotic convergence and convergence in finite time.

By part (i), for all $w_{t-1} \underset{(>)}{<} \bar{w}^{b}$ then $g^{b}\left(w_{t-1}\right) \underset{(<)}{>} 0$.

$F^{b}\left(w_{t-1}\right)$ is strictly increasing in $w_{t-1}$ for $0<w_{t-1}<\hat{w}$. Hence

\section{Asymptotic convergence}

- if $w_{0}<\bar{w}^{b}<\hat{w}$ then $g\left(w_{0}\right)>0$ and $\forall t \geq 1 w_{t}>w_{t-1} \Rightarrow g\left(w_{t}\right)>0$

- if $w_{0}>\bar{w}^{b}$, and $\bar{w}^{b}<\hat{w}$ then $g\left(w_{0}\right)<0$ and $\forall t \geq 1 w_{t}<w_{t-1} \Rightarrow g\left(w_{t}\right)<0$

$\underline{\text { Convergence in finite time }}$

For $\bar{w}^{b}>\hat{w} \Rightarrow \bar{w}^{b}=(1-\beta) f(\bar{k})$

- if $w_{0}<\hat{w}<\bar{w}^{b} \Rightarrow g\left(\bar{w}^{b}\right)=0<g(\hat{w})<g\left(w_{0}\right)$

by (i) and (ii), $\exists$ a unique $t^{*}<\infty$, such that $\left\{\begin{array}{c}w_{t^{*}-1}<\hat{w} \\ w_{t^{*}} \geq \hat{w}\end{array}\right.$, hence, $w_{t^{*}+1}=(1-\beta) f(\bar{k})=\bar{w}^{b}$, the economy will converge to the s.s. after $t^{*}+1$ periods.

- if $w_{0}>\hat{w} \Rightarrow w_{1}=(1-\beta) f(\bar{k})=\bar{w}^{b}$, the economy will converge after one period.

\section{A.3 Consequences of Financial Intermediation}

Proof of proposition 6.1 (Inefficient level of investment under Financial Autarky).

Let $k^{a}(w)$ and $k^{b}(w)$ be the optimal choice function under autarky and financial intermediation For $\left.\sigma>0,\left\{w^{*}, \widetilde{w}\right\} \subset\right] \underline{k}, \widehat{w}[$

(i) If $w \in] \underline{k}, w^{*}\left[, k^{a}(w)=w>k^{b}(w)\right.$; if $\left.w \in\right] \underline{k}, \widetilde{w}\left[, k^{a}(w)>k^{b}(w)=\underline{k}\right.$, then for $w \in$ ]$\underline{k}, \max \left(w^{*}, \widetilde{w}\right)\left[, k^{a}(w)>k^{b}(w)\right.$.

(ii) At $w=\widehat{w}, k^{a}(w)<k \max <k^{b}(w)=\bar{k}$; therefore since $k^{a}(w)$ and $k^{b}(w)$ are strictly increasing strictly and concave over $\left[\max \left(w^{*}, \widetilde{w}\right), \widehat{w}[\right.$, it exists a unique $m \in] \max \left(w^{*}, \widetilde{w}\right), \widehat{w}[\operatorname{such}$ that $k^{a}(m)=k^{b}(m)$. 
Proof of proposition 6.2 (Growth under Financial Autarky and Financial Intermediation).

$\underline{\sigma>1}$. Exists at least one $w_{u} \in \underline{k}, m\left[\right.$ such that $F^{a}\left(w_{u}\right)=F^{b}\left(w_{u}\right)$

(R1) $w \in(0, \underline{k}): \frac{F^{a}(w)}{F^{b}(w)}=\frac{(\pi \gamma+1-\pi)}{\left(\lambda^{*} \gamma+1-\lambda^{*}\right)}>1 \Longleftrightarrow \lambda^{*}>\pi \Longleftrightarrow \sigma>1$

(R2) for $w \geq m$ with $m \in(\widetilde{w}, \widehat{w})$ as defined in Prop.6.1: $\frac{F^{a}(w)}{F^{b}(w)}=\frac{(\pi \gamma+1-\pi) h\left(k^{a}(w)\right)}{h\left(k^{b}(w)\right)}$ Since $w \geq m \Rightarrow$ $k^{a}(w) \leq k^{b}(w) \Rightarrow F^{a}(w)<F^{b}(w)$

form (R1) and (R2) by continuity, it exists at least one level of wealth $\left.w_{u} \in\right] \underline{k}, m\left[\right.$ such that $F^{a}\left(w_{u}\right)=$ $F^{b}\left(w_{u}\right)$

\section{Uniqueness of $w_{u}$ :}

(R3) $F^{a}(w)$ is strictly increasing, strictly concave over $] \underline{k}, m\left[\right.$ and $F^{b}(w)$ is strictly increasing and affine over $] \underline{k}, \widetilde{w}] T$ Therefore it can be at most one root of $F^{a}(w)=F^{b}(w)$ over $] \underline{k}, \widetilde{w}$. If there is one root over $] \underline{k}, \widetilde{w}], F^{\prime a}(\widetilde{w})<F^{\prime(-) b}(\widetilde{w})$.

Case (i): $F^{a}(\widetilde{w})>F^{b}(\widetilde{w})$. By $(\mathrm{R} 3), F^{a}(w)>F^{b}(w)$ over $] \underline{k}, \widetilde{w}\left[\right.$. Since $F^{a}(w)$ and $F^{b}(w)$ are strictly increasing and strictly concave over $] \widetilde{w}, m\left[\right.$ and $F^{a}(m)<F^{b}(m), F^{a}(w)=F^{b}(w)$ must have a unique root over $] \widetilde{w}, m[$

Case (ii): $F^{a}(\widetilde{w}) \leq F^{b}(\widetilde{w})$. By $(\mathrm{R} 3), F^{a}(w)=F^{b}(w)$ as exactly one root over $\left.] \underline{k}, \widetilde{w}\right]$. Let's show that in this case cannot be a root over $] \widetilde{w}, m\left[\right.$. Consider the unique affine function $G(w)$ with $G^{\prime}(w)=e$, such that $G(\widetilde{w})=F^{b}(\widetilde{w})$ and $G(m)=F^{b}(m)$.

- If $F^{\prime(-) b}(\widetilde{w})<e \Rightarrow F^{\prime a}(\widetilde{w})<F^{\prime(-) b}(\widetilde{w})<e$. $F^{a}$ is strictly concave $\Rightarrow F^{a}(w)<G(w) \leq F^{b}(w)$ over $] \widetilde{w}, m]$.

- If $F^{\prime(-) b}(\widetilde{w}) \geq e$, consider the function $L(w)=F^{b}(w)$ for $w \leq \widetilde{w}$, and $L(w)=G(w)$ for $w>\widetilde{w}$. $L(w)$ is continuous, strictly increasing and concave over $] \underline{k}, m\left[\right.$. Then $L(w)=F^{a}(w)$ has a exactly one root over $] \underline{k}, \widetilde{w}]$ as $F^{a}(\widetilde{w}) \leq L(w)$ and no root over $\left.] \widetilde{w}, m\right]$. As $F^{b}(w) \geq L(w)$, $F^{b}(w)=F^{a}(w)$ has exactly one root over $] \underline{k}, m[$.

$\underline{\sigma \leq 1}$

(R4) Consider $\sigma=1$. For $w \leq \underline{k}, F^{a}(w)=F^{b}(w)$, and at $w=\underline{k}, F^{\prime(+) a}(\underline{k})>F^{\prime(+) b}(\underline{k}) .^{30}$

$$
30 \frac{F^{a^{\prime}}(\underline{k})}{F^{b^{\prime}}(\underline{k})}=\left\{\begin{array}{cc}
\frac{(\pi \gamma+1-\pi)}{(1-\gamma)\left(1-\lambda^{*}\right)} & \text { for } \sigma>0 \\
\pi \gamma+1-\pi<1 & \text { for } \sigma=0
\end{array}, \sigma=1 \Rightarrow \frac{F^{a^{\prime}}(\underline{k})}{F^{b \prime}(\underline{\underline{k}})}=\frac{1}{1-\gamma}\left(\frac{\gamma \pi}{1-\pi}+1\right)>1\right.
$$


Then it exists a range $\left.] \underline{k}, w^{\prime}\right)$ over which $F^{a}(w)>F^{b}(w)$. Thus by the same reasoning as above, it exist a unique $\left.w_{u} \in\right] \underline{k}, \widetilde{w}\left[\operatorname{such}\right.$ that $F^{a}\left(w_{u}\right)=F^{b}\left(w_{u}\right)$. In this case $F^{a}(w)$ and $F^{b}(w)$ are intersecting continuously over $[0, \underline{k})$, and twice over $[\underline{k}, m]$ at $\underline{k}$ and $w_{u}$.

(R5) Intermediate risk aversion. By (R4) when $\sigma \rightarrow 1^{-}, F^{a}(\underline{k}) \nearrow F^{b}(\underline{k})$. We know that $F^{\prime(-) b}(\underline{k})>$ $F^{\prime(+) b}(\underline{k})$ and $F^{\prime(-) a}(\underline{k})=F^{\prime(-) a}(\underline{k})$. Therefore for $\sigma$ sufficiently close to one, it exists a point $w_{L}>\underline{k}$ such that $F^{a}\left(w_{L}\right)=F^{b}\left(w_{L}\right)$ and $F^{\prime a}\left(w_{L}\right) \geq F^{\prime b}\left(w_{L}\right)$. Since $F^{a}(m)<F^{b}(m)$ by continuity (following a parallel argument to (R3)) there must exist a unique $w_{u}$ such that $F^{a}\left(w_{u}\right)=F^{b}\left(w_{u}\right)$ and $F^{\prime a}\left(w_{u}\right) \leq F^{\prime b}\left(w_{u}\right)$.

$\Rightarrow$ Then by continuity, it exists a range $\left(\sigma_{1}, 1\right)$, such that $F^{a}$ and $F^{b}$ are intersecting in $w_{L}$ and $w_{u}$ $\in] \underline{k}, m\left[, w_{L} \leq w_{u}\right.$ and $w_{L}<w^{*}$.

(R6) Low risk aversion. As $\sigma \rightarrow 0: \lambda^{*} \rightarrow 0, \widetilde{w} \rightarrow \underline{k},\left.k_{o p t}^{b}(w)\right|_{w \leq \hat{w}} \rightarrow w,\left.F^{b}(w)\right|_{w \leq \hat{w}} \rightarrow(1-\beta) f(w)$, and $F^{a}(w)=(1-\beta)(\pi \gamma+1-\pi) f\left(k^{b}(w)\right)<(1-\beta) f(w)$

$\Rightarrow$ by continuity it exists a range of $\left[0, \sigma_{o}\right]$ such that growth with financial intermediation strictly dominates growth in autarky

(R7) Relative Growth and risk aversion. For all $w \leq\left. w^{*} \frac{d \frac{F^{a}(w)}{F^{b}(w)}}{d \sigma}\right|_{0<\sigma<1}>0$.

$\frac{d^{(-)} \frac{F^{a}\left(w^{*}\right)}{F^{b}\left(w^{*}\right)}}{d \sigma}>\frac{d^{(+)} \frac{F^{a}\left(w^{*}\right)}{F^{b}\left(w^{*}\right)}}{d \sigma} .^{31} \Rightarrow$ From (R5), (R6) and (R7) there exists a $\underline{\sigma} \in\left[\sigma_{o}, \sigma_{1}\right]$ such that:

For $0 \leq \sigma<\underline{\sigma} \quad F^{a}(w)<F^{b}(w) \forall w>0$

For $\underline{\sigma}<\sigma<1 F^{a}(w)<F^{b}(w) \forall w \in \Re^{+}-\left[w_{u}, w_{L}\right]$ with $\left.\left[w_{u}, w_{L}\right] \in\right] \underline{k}, m[$

$\left.31 \frac{d F^{b}}{d \sigma}\right|_{w \leq \hat{w}}<0,\left.\quad \frac{d F^{b}}{d \sigma}\right|_{w \leq \hat{w}} \begin{cases}=0 & \text { for } w \leq w^{*} \\ <0 & \text { for } w>w^{*}\end{cases}$ 


\section{B Estimation}

Table 2: Countries included in the estimation, and income classifications

\begin{tabular}{|c|c|c|c|c|c|c|c|}
\hline CODE & Country & $\begin{array}{c}\text { World Bank } \\
\text { Classification }\end{array}$ & Decile $^{2}$ & CODE & Country & $\begin{array}{c}\text { World Bank } \\
\text { Classification }\end{array}$ & Decile $^{2}$ \\
\hline$\overline{\text { ARG }}$ & Argentina & MH & 7 & JPN & Japan & OECD & 10 \\
\hline AUS & Australia & OECD & 9 & KEN & Kenya & L & 2 \\
\hline AUT & Austria & OECD & 10 & KOR & Korea, Rep. & OECD & 8 \\
\hline BEL & Belgium & OECD & 9 & LKA & Sri Lanka & ML & 3 \\
\hline BFA & Burkina Faso & L & 1 & MAR & Morocco & ML & 4 \\
\hline BGD & Bangladesh & $\mathbf{L}$ & 2 & MDG & Madagascar & $\mathbf{L}$ & 1 \\
\hline BOL & Bolivia & ML & 4 & MEX & Mexico & MH & 6 \\
\hline BRA & Brazil & ML & 7 & MWI & Malawi & $\mathbf{L}$ & 1 \\
\hline BWA & Botswana & MH & 6 & MYS & Malaysia & MH & 7 \\
\hline CAN & Canada & OECD & 9 & NER & Niger & $\mathbf{L}$ & 1 \\
\hline CHE & Switzerland & OECD & 10 & NGA & Nigeria & $\mathbf{L}$ & 1 \\
\hline CHL & Chile & MH & 7 & NIC & Nicaragua & $\mathbf{L}$ & 3 \\
\hline CHN & China & ML & 2 & NLD & Netherlands & OECD & 10 \\
\hline CIV & Cote d'Ivoire & $\mathbf{L}$ & 3 & NOR & Norway & OECD & 10 \\
\hline COG & Congo, Rep. & L & 4 & NZL & New Zealand & OECD & 9 \\
\hline COL & Colombia & ML & 6 & PAK & Pakistan & L & 3 \\
\hline CRI & Costa Rica & MH & 7 & PAN & Panama & MH & 6 \\
\hline DEU & Germany & OECD & 10 & PER & Peru & ML & 6 \\
\hline DNK & Denmark & OECD & 10 & PHL & Philippines & ML & 4 \\
\hline DOM & Dominican Republic & ML & 5 & PNG & Papua New Guinea & $\mathbf{L}$ & 4 \\
\hline DZA & Algeria & ML & 5 & PRT & Portugal & OECD & 8 \\
\hline ECU & Ecuador & ML & 5 & PRY & Paraguay & ML & 5 \\
\hline EGY & Egypt, Arab Rep. & ML & 4 & SEN & Senegal & $\mathbf{L}$ & 3 \\
\hline ESP & Spain & OECD & 8 & SGP & Singapore & MH & 8 \\
\hline FIN & Finland & OECD & 9 & SLE & Sierra Leone & $\mathbf{L}$ & 1 \\
\hline FRA & France & OECD & 9 & SLV & El Salvador & ML & 5 \\
\hline GBR & United Kingdom & OECD & 9 & SWE & Sweden & OECD & 10 \\
\hline GHA & Ghana & $\mathbf{L}$ & $\mathbf{2}$ & SYR & Syrian Arab Republic & ML & 4 \\
\hline GMB & Gambia, The & $\mathbf{L}$ & 2 & TGO & Togo & $\mathbf{L}$ & 2 \\
\hline GRC & Greece & OECD & 8 & THA & Thailand & ML & 6 \\
\hline GTM & Guatemala & ML & 4 & TTO & Trinidad and Tobago & MH & 7 \\
\hline HND & Honduras & ML & 3 & TUN & Tunisia & ML & 5 \\
\hline HTI & Haiti & $\mathbf{L}$ & $\mathbf{2}$ & TUR & Turkey & ML & 6 \\
\hline IDN & Indonesia & $\mathbf{L}$ & 4 & UGA & Uganda & $\mathbf{L}$ & 1 \\
\hline IND & India & $\mathbf{L}$ & 2 & URY & Uruguay & MH & 7 \\
\hline IRL & Ireland & OECD & 8 & USA & United States & OECD & 10 \\
\hline IRN & Iran, Islamic Rep. & ML & 5 & VEN & Venezuela, RB & MH & 7 \\
\hline ISL & Iceland & OECD & 9 & ZAF & South Africa & ML & 7 \\
\hline ISR & Israel & MH & 8 & ZAR & Congo, Dem. Rep. & $\mathbf{L}$ & 1 \\
\hline ITA & Italy & OECD & 8 & ZMB & Zambia & $\mathbf{L}$ & 3 \\
\hline JAM & Jamaica & ML & 6 & ZWE & Zimbabwe & $\mathbf{L}$ & 3 \\
\hline JOR & Jordan & ML & 5 & & & & \\
\hline
\end{tabular}


Table 3: Variables and Sources

\begin{tabular}{|c|c|c|}
\hline Variable & Source & Definition \\
\hline GDP Level and Growth & $\begin{array}{l}\text { World Development Indicators, and Penn } \\
\text { World data set. }\end{array}$ & Real per capita GDP in 1995 US dollars. \\
\hline Average years of & Barro and Lee (1996) & Average years of schooling in the population over \\
\hline $\begin{array}{l}\text { schooling } \\
\text { Government size }\end{array}$ & & 25. \\
\hline Inflation rate & International Financial Statistics & Log difference of Consumer Price Index. \\
\hline Openness to trade & World Development Indicators & $\begin{array}{l}\text { Sum of real exports and imports as share of real } \\
\text { GDP. }\end{array}$ \\
\hline Liquid Liabilities & International Financial Statistics & $\begin{array}{l}\text { Ratio of liquid liabilities (average of year } t \text { and } t- \\
\text { 1) to year t GDP. }\end{array}$ \\
\hline Private Credit & International Financial Statistics & $\begin{array}{l}\text { Ratio of credit by deposit money banks and other } \\
\text { financial institutions to the private sector } \\
\text { (average of year } t \text { and } t-1 \text { ) to year } t \text { GDP. }\end{array}$ \\
\hline Frequency of Crises & Caprio and Klingebiel $(1999,2003)$ & $\begin{array}{l}\text { Number of years with banking crises within the } \\
\text { period dived by the length of the period } 5 \text {. }\end{array}$ \\
\hline
\end{tabular}


Table 4: Financial Development and Growth, No Wealth Effects

\begin{tabular}{|c|c|c|c|c|c|c|c|c|}
\hline \multirow[b]{2}{*}{ Regressors } & \multicolumn{3}{|c|}{ Private Credit } & \multirow[b]{2}{*}{ p-val } & \multicolumn{3}{|c|}{ Liquid Liabilities } & \multirow[b]{2}{*}{ p-val } \\
\hline & Coefficient & p-val & Coefficient & & Coefficient & p-val & Coefficient & \\
\hline Constant & -1.18 & 0.14 & -1.70 & 0.03 & -1.96 & 0.00 & -1.67 & 0.00 \\
\hline Initial Income per Capita & -0.42 & 0.00 & -0.47 & 0.00 & -0.31 & 0.00 & -0.37 & 0.00 \\
\hline Avg. secondary schooling & 1.76 & 0.00 & 1.68 & 0.00 & 1.47 & 0.00 & 1.34 & 0.00 \\
\hline Government size & -0.46 & 0.02 & -0.32 & 0.14 & -0.69 & 0.00 & -0.93 & 0.00 \\
\hline Inflation Rate & -0.08 & 0.17 & 0.07 & 0.52 & -0.10 & 0.13 & 0.10 & 0.27 \\
\hline Trade Openness & 1.31 & 0.00 & 1.15 & 0.00 & 1.22 & 0.00 & 1.35 & 0.00 \\
\hline Frequency of Crisis & & & -2.73 & 0.00 & & & -2.94 & 0.00 \\
\hline Financial Development & 1.09 & 0.00 & 1.23 & 0.00 & 1.40 & 0.00 & 1.72 & 0.00 \\
\hline Dummy 71-75 & -0.98 & 0.00 & -1.18 & 0.00 & -0.72 & 0.00 & -1.05 & 0.00 \\
\hline Dummy 76-80 & -1.97 & 0.00 & -2.11 & 0.00 & -1.58 & 0.00 & -1.88 & 0.00 \\
\hline Dummy 81-85 & -4.00 & 0.00 & -3.65 & 0.00 & -3.65 & 0.00 & -3.46 & 0.00 \\
\hline Dummy 86-90 & -3.30 & 0.00 & -3.06 & 0.00 & -3.03 & 0.00 & -2.86 & 0.00 \\
\hline Dummy 91-94 & -3.78 & 0.00 & -3.31 & 0.00 & -3.36 & 0.00 & -3.18 & 0.00 \\
\hline Dummy 96-2000 & -3.87 & 0.00 & -3.39 & 0.00 & -3.56 & 0.00 & -3.36 & 0.00 \\
\hline Sargan Test (P-value) & & 0.25 & & 0.36 & & 0.33 & & 0.32 \\
\hline 2nd Order Serial Corr.(P-Value) & & 0.33 & & 0.25 & & 0.46 & & 0.32 \\
\hline
\end{tabular}

Table 5: Financial Development and Growth, World Bank Classification

\begin{tabular}{|c|c|c|c|c|c|c|c|c|}
\hline \multirow[b]{2}{*}{ Regressors } & \multicolumn{3}{|c|}{ Private Credit } & \multirow[b]{2}{*}{ p-val } & \multicolumn{3}{|c|}{ Liquid Liabilities } & \multirow[b]{2}{*}{ p-val } \\
\hline & Coefficient & p-val & Coefficient & & Coefficient & p-val & Coefficient & \\
\hline Constant & 1.94 & 0.23 & 4.42 & 0.01 & 8.99 & 0.00 & 11.01 & 0.00 \\
\hline Initial Income per Capita & -0.70 & 0.00 & -1.13 & 0.00 & -1.44 & 0.00 & -1.65 & 0.00 \\
\hline Avg. secondary schooling & 1.59 & 0.00 & 1.26 & 0.00 & 0.91 & 0.00 & 0.59 & 0.00 \\
\hline Government size & -0.62 & 0.01 & -0.33 & 0.18 & -0.84 & 0.00 & -1.03 & 0.00 \\
\hline Inflation Rate & -0.10 & 0.19 & -0.06 & 0.55 & -0.08 & 0.31 & -0.07 & 0.39 \\
\hline Trade Openness & 1.26 & 0.00 & 1.11 & 0.00 & 1.44 & 0.00 & 1.31 & 0.00 \\
\hline Frequency of Crisis & & & -3.09 & 0.00 & & & -3.58 & 0.00 \\
\hline Fin. Dev. Low Inc. Countries & 0.65 & 0.00 & 0.58 & 0.01 & 0.24 & 0.44 & 0.34 & 0.34 \\
\hline Fin. Dev. Middle-Low Inc. Countries & 1.15 & 0.00 & 1.55 & 0.00 & 1.32 & 0.00 & 1.62 & 0.00 \\
\hline Fin. Dev. Middle-High Inc. Countries & 1.17 & 0.00 & 1.35 & 0.00 & 1.38 & 0.00 & 1.56 & 0.00 \\
\hline Fin. Dev. OECD Countries & 1.15 & 0.00 & 1.69 & 0.00 & 1.94 & 0.00 & 2.30 & 0.00 \\
\hline Dummy 71-75 & -0.86 & 0.00 & -0.77 & 0.00 & -0.37 & 0.07 & -0.52 & 0.02 \\
\hline Dummy 76-80 & -1.79 & 0.00 & -1.66 & 0.00 & -1.06 & 0.00 & -1.05 & 0.00 \\
\hline Dummy 81-85 & -3.66 & 0.00 & -3.10 & 0.00 & -2.78 & 0.00 & -2.20 & 0.00 \\
\hline Dummy 86-90 & -3.09 & 0.00 & -2.48 & 0.00 & -2.16 & 0.00 & -1.58 & 0.00 \\
\hline Dummy 91-94 & -3.57 & 0.00 & -2.61 & 0.00 & -2.44 & 0.00 & -1.61 & 0.00 \\
\hline Dummy 96-2000 & -3.51 & 0.00 & -2.70 & 0.00 & -2.35 & 0.00 & -1.66 & 0.00 \\
\hline Sargan Test (P-value) & & 0.28 & & 0.43 & & 0.27 & & 0.40 \\
\hline 2nd Order Serial Corr.(P-Value) & & 0.36 & & 0.31 & & 0.56 & & 0.39 \\
\hline Tests: Ho: $\square=\square_{M L}$ & & 0.00 & & 0.00 & & 0.00 & & 0.00 \\
\hline Ho: $\square_{\mathrm{MH}}=\square_{\mathrm{ML}}$ & & 0.93 & & 0.27 & & 0.72 & & 0.64 \\
\hline Ho: $\square_{\text {oecd }}=\square_{\mathrm{ML}}$ & & 0.98 & & 0.48 & & 0.00 & & 0.00 \\
\hline
\end{tabular}


Table 6: Financial Development and Growth, Decile Classification

\begin{tabular}{|c|c|c|c|c|c|c|c|c|c|c|c|c|}
\hline \multirow[b]{2}{*}{ Regressors } & \multicolumn{6}{|c|}{ Private Credit } & \multicolumn{6}{|c|}{ Liquid Liabilities } \\
\hline & Coefficient & Std.Err. & p-val & Coefficient & Std.Err. & p-val & Coefficient & Std.Err. & p-val & Coefficient & Std.Err. & p-val \\
\hline Constant & 19.50 & 3.49 & 0.00 & 14.42 & 3.02 & 0.00 & 18.75 & 3.49 & 0.00 & 11.64 & 3.02 & 0.00 \\
\hline Initial Income per Capita & -3.04 & 0.41 & 0.00 & -2.30 & 0.37 & 0.00 & -2.82 & 0.41 & 0.00 & -1.82 & 0.37 & 0.00 \\
\hline Avg. secondary schooling & 0.88 & 0.25 & 0.00 & 0.72 & 0.25 & 0.00 & 0.43 & 0.25 & 0.05 & 0.33 & 0.25 & 0.14 \\
\hline Government size & -0.44 & 0.34 & 0.19 & -0.33 & 0.35 & 0.35 & -0.64 & 0.34 & 0.11 & -0.32 & 0.35 & 0.49 \\
\hline Inflation Rate & -0.12 & 0.10 & 0.24 & -0.04 & -0.03 & 0.22 & 0.09 & 0.10 & 0.42 & -0.07 & -0.04 & 0.11 \\
\hline Trade Openness & 1.02 & 0.24 & 0.00 & 1.25 & 0.20 & 0.00 & 0.64 & 0.24 & 0.00 & 0.80 & 0.20 & 0.00 \\
\hline Frequency of Crisis & & & & -2.83 & 0.53 & 0.00 & & & & -4.37 & 0.53 & 0.00 \\
\hline Decile 1 & -1.13 & 0.38 & 0.00 & -0.87 & 0.33 & 0.01 & -1.02 & 0.38 & 0.00 & -0.64 & 0.33 & 0.08 \\
\hline Decile 2 & -0.28 & 0.43 & 0.50 & -0.37 & 0.37 & 0.31 & -0.64 & 0.43 & 0.07 & -0.83 & 0.37 & 0.04 \\
\hline Decile 3 & 0.14 & 0.28 & 0.62 & 0.27 & 0.28 & 0.34 & 0.51 & 0.28 & 0.04 & 0.54 & 0.28 & 0.08 \\
\hline Decile 4 & 1.47 & 0.31 & 0.00 & 1.51 & 0.26 & 0.00 & 1.92 & 0.31 & 0.00 & 2.13 & 0.26 & 0.00 \\
\hline Decile 5 & 1.61 & 0.30 & 0.00 & 1.74 & 0.27 & 0.00 & 1.57 & 0.30 & 0.00 & 1.60 & 0.27 & 0.00 \\
\hline Decile 6 & 0.91 & 0.31 & 0.00 & 0.97 & 0.25 & 0.00 & 2.15 & 0.31 & 0.00 & 1.93 & 0.25 & 0.00 \\
\hline Decile 7 & 1.68 & 0.27 & 0.00 & 1.31 & 0.26 & 0.00 & 1.86 & 0.27 & 0.00 & 1.13 & 0.26 & 0.00 \\
\hline Decile 8 & 2.79 & 0.33 & 0.00 & 2.58 & 0.28 & 0.00 & 2.87 & 0.33 & 0.00 & 2.56 & 0.28 & 0.00 \\
\hline Decile 9 & 3.23 & 0.37 & 0.00 & 2.64 & 0.42 & 0.00 & 3.10 & 0.37 & 0.00 & 2.33 & 0.42 & 0.00 \\
\hline Decile 10 & 2.64 & 0.29 & 0.00 & 2.05 & 0.29 & 0.00 & 2.94 & 0.29 & 0.00 & 2.05 & 0.29 & 0.00 \\
\hline Dummy 71-75 & -0.30 & 0.23 & 0.20 & -0.60 & 0.23 & 0.01 & -0.27 & 0.23 & 0.23 & -0.50 & 0.23 & 0.05 \\
\hline Dummy 76-80 & -0.89 & 0.32 & 0.01 & -1.22 & 0.29 & 0.00 & -0.89 & 0.32 & 0.00 & -1.03 & 0.29 & 0.00 \\
\hline Dummy 81-85 & -2.70 & 0.37 & 0.00 & -2.81 & 0.30 & 0.00 & -2.58 & 0.37 & 0.00 & -2.39 & 0.30 & 0.00 \\
\hline Dummy 86-90 & -2.19 & 0.28 & 0.00 & -2.04 & 0.26 & 0.00 & -2.07 & 0.28 & 0.00 & -1.60 & 0.26 & 0.00 \\
\hline Dummy 91-94 & -2.27 & 0.35 & 0.00 & -2.26 & 0.33 & 0.00 & -2.03 & 0.35 & 0.00 & -1.67 & 0.33 & 0.00 \\
\hline Dummy 96-2000 & -2.29 & 0.37 & 0.00 & -2.03 & 0.34 & 0.00 & -1.85 & 0.37 & 0.00 & -1.49 & 0.34 & 0.00 \\
\hline Sargan Test (P-value) & & & 0.54 & & & 0.55 & & & 0.36 & & & 0.42 \\
\hline 2nd Order Serial Corr.(P-Value) & & & 0.54 & & & 0.44 & & & 0.51 & & & 0.25 \\
\hline
\end{tabular}


Figure 1: Contribution of Financial Development to Economic Growth. Wealth Effects, Decile Classification.

(Private Credit)

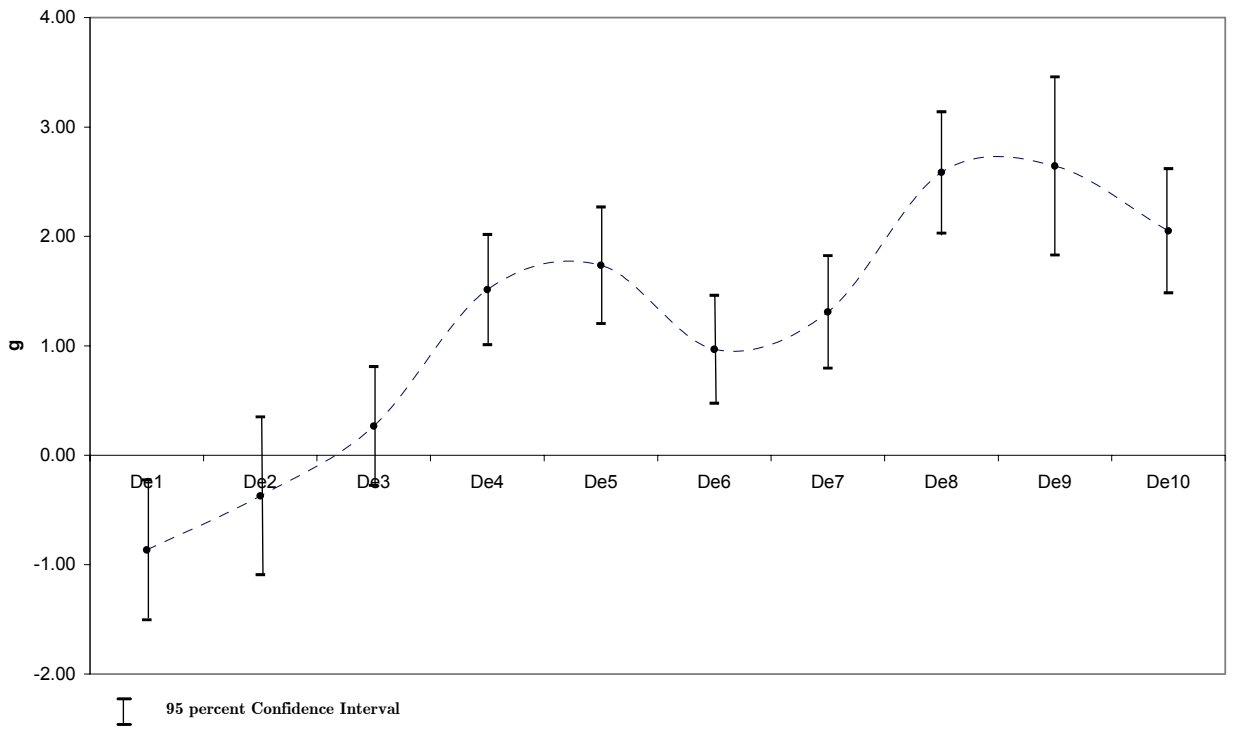

Figure 2: Contribution of Financial Development to Economic Growth.

Wealth Effects, Decile Classification.

(Liquid Liabilities)

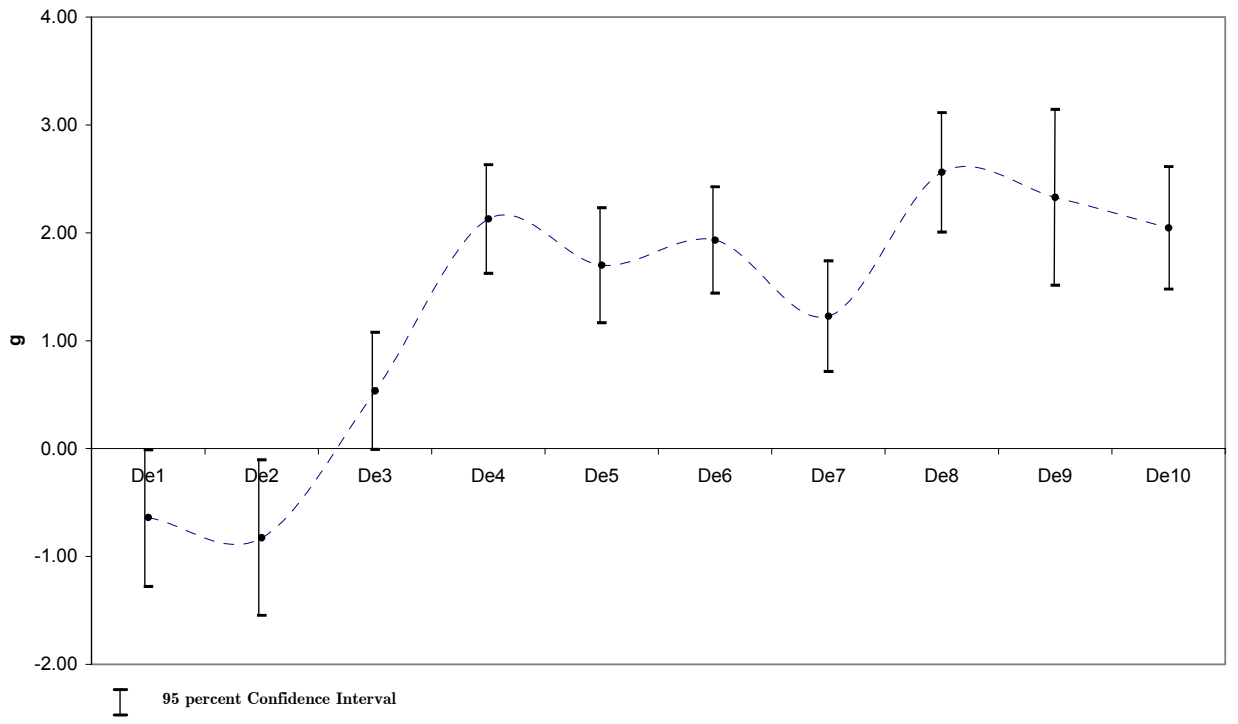


Table 7: Financial Development and Growth, Linear-Quadratic Specification

\begin{tabular}{|c|c|c|c|c|c|c|}
\hline \multirow[b]{2}{*}{ Regressors } & \multicolumn{3}{|c|}{ Private Credit } & \multicolumn{3}{|c|}{ Liquid Liabilities } \\
\hline & Coefficient & Std.Err. & p-val & Coefficient & Std.Err. & p-val \\
\hline Constant & 0.97 & 2.91 & 0.74 & 3.71 & 4.34 & 0.39 \\
\hline Initial Income per Capita & -0.45 & 0.52 & 0.39 & -0.59 & 0.66 & 0.37 \\
\hline Avg. secondary schooling & 1.48 & 0.20 & 0.00 & 1.19 & 0.19 & 0.00 \\
\hline Government size & -0.78 & 0.30 & 0.01 & -1.30 & 0.20 & 0.00 \\
\hline Inflation Rate & -0.09 & 0.11 & 0.40 & -0.09 & 0.10 & 0.35 \\
\hline Trade Openness & 1.45 & 0.22 & 0.00 & 1.67 & 0.20 & 0.00 \\
\hline Frequency of Crisis & -3.50 & 0.32 & 0.00 & -3.86 & 0.37 & 0.00 \\
\hline Financial Development & -5.54 & 1.92 & 0.00 & -7.36 & 2.02 & 0.00 \\
\hline Financial Dev. ${ }^{*} \mathbf{y}_{0}$ & 1.61 & 0.41 & 0.00 & 2.06 & 0.39 & 0.00 \\
\hline Financial Dev.* $\left(y_{0}\right)^{2}$ & -0.10 & 0.02 & 0.00 & -0.12 & 0.02 & 0.00 \\
\hline Dummy 71-75 & -0.87 & 0.17 & 0.00 & -0.64 & 0.16 & 0.00 \\
\hline Dummy 76-80 & -1.62 & 0.22 & 0.00 & -1.34 & 0.18 & 0.00 \\
\hline Dummy 81-85 & -3.05 & 0.26 & 0.00 & -2.66 & 0.19 & 0.00 \\
\hline Dummy 86-90 & -2.45 & 0.21 & 0.00 & -2.10 & 0.17 & 0.00 \\
\hline Dummy 91-94 & -2.84 & 0.18 & 0.00 & -2.51 & 0.18 & 0.00 \\
\hline Dummy 96-2000 & -2.85 & 0.21 & 0.00 & -2.58 & 0.23 & 0.00 \\
\hline Sargan Test (P-value) & & & 0.44 & & & 0.50 \\
\hline 2nd Order Serial Corr.(P-Value) & & & 0.24 & & & 0.29 \\
\hline \multicolumn{7}{|c|}{ Income Thresholds in 1995 US dollars } \\
\hline $\mathbf{y}_{0}^{1}$ & 131.2 & & & 167.7 & & \\
\hline $\mathbf{y}_{0}{ }^{2}$ & $3,835.6$ & & & $4,711.5$ & & \\
\hline $\mathbf{y}_{0}^{3}$ & $112,155.1$ & & & $132,382.9$ & & \\
\hline $\operatorname{Min}\left\{y_{0}\right\}$ in sample & 89.6 & & & & & \\
\hline $\operatorname{Max}\left\{y_{0}\right\}$ in sample & $45,951.9$ & & & & & \\
\hline
\end{tabular}

\section{Simulation}

The parameters used in the simulation are:

\begin{tabular}{||ll||}
\hline \hline Factor Productivity & $A=3$ \\
Capital Share & $\beta=0.4$ \\
Liquidation Value & $\gamma=0.5$ \\
Probability of Liquidity Shock & $\pi=0.4$ \\
Coefficient of Risk Aversion & $\sigma=2$ \\
Initial wealth & $w_{0}=0.0000001$ \\
\hline \hline
\end{tabular}


Figure 3: Optimal Investment in Capital $k_{\text {opt }}(w)$, and Optimal Liquidation $\boldsymbol{\lambda}_{\text {opt }}(\mathbf{w})$ Autarky and Financial Intermediation
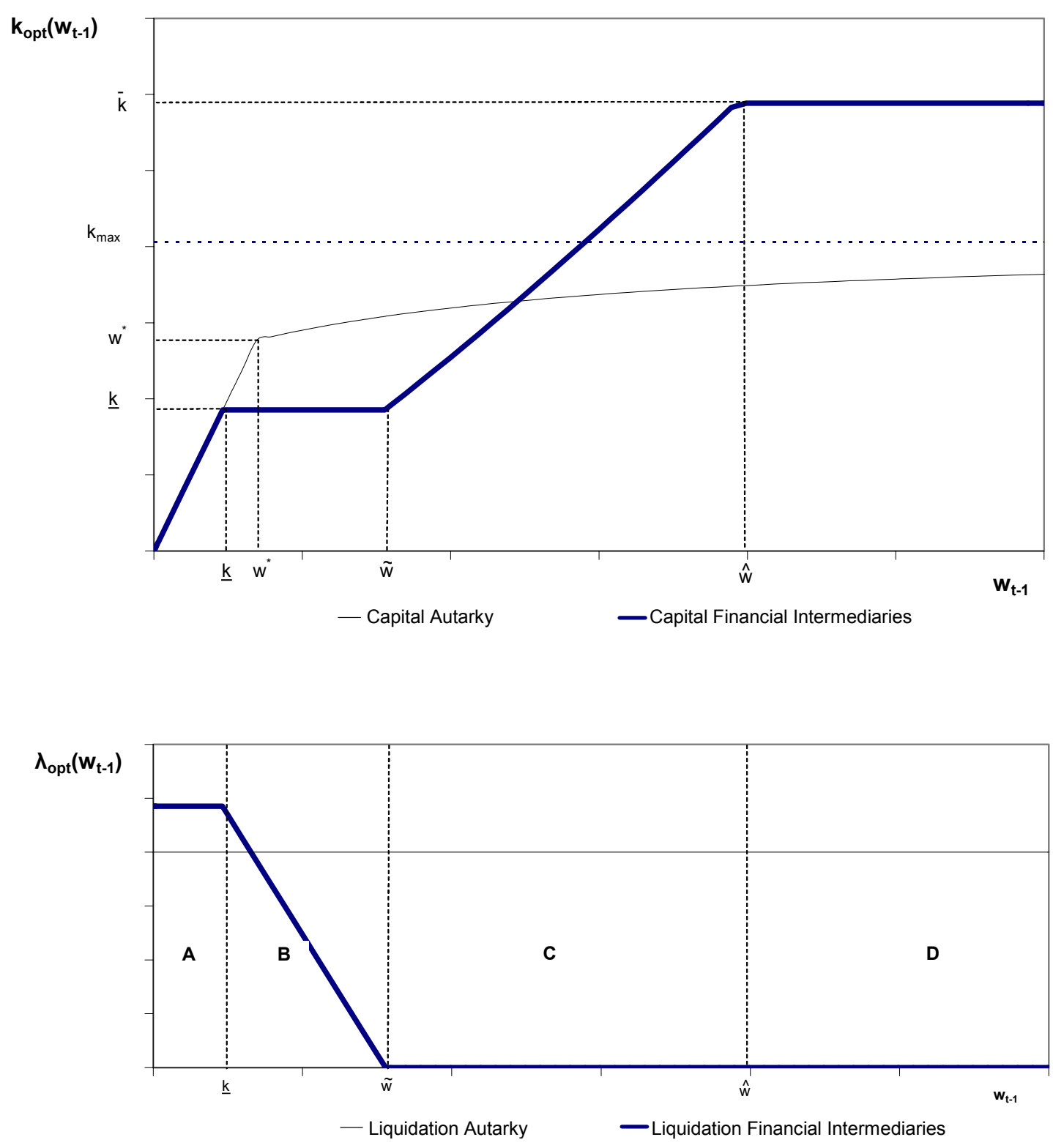
Figure 4: Comparison of the Dynamics under Autarky and Financial Intermediation

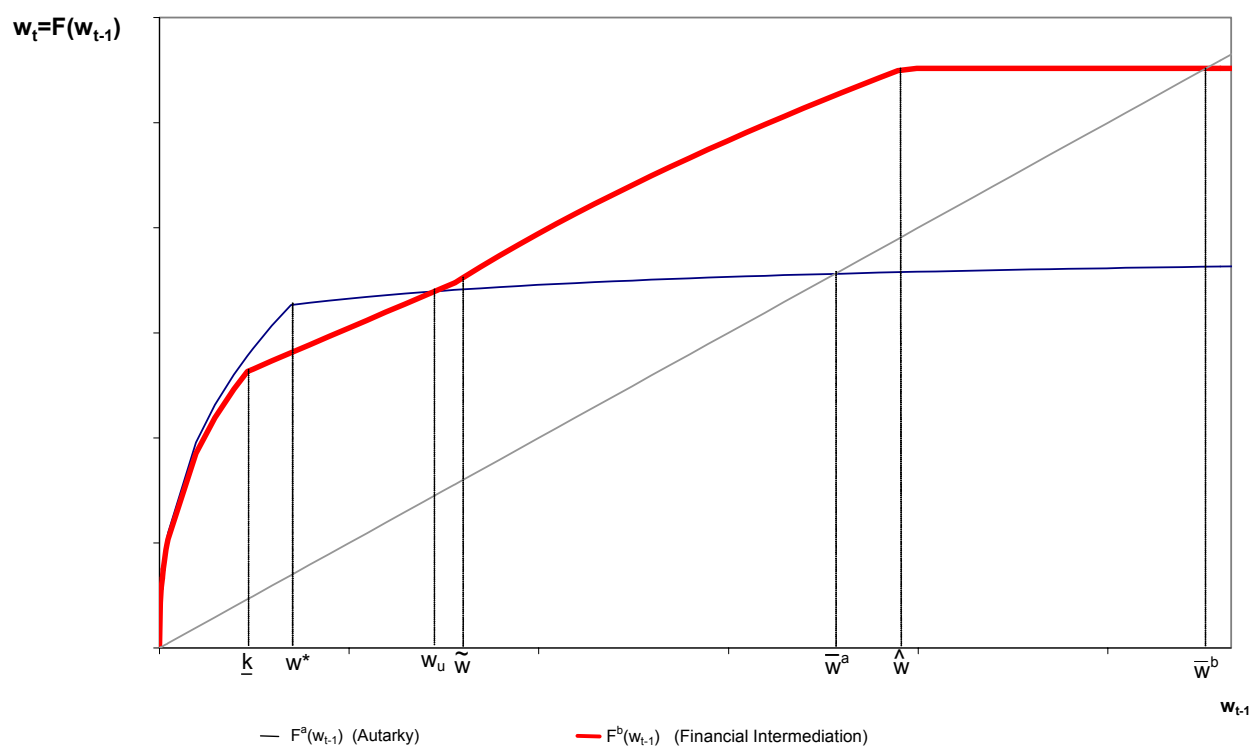

Figure 5: The Growth Consequences of Financial Intermediation

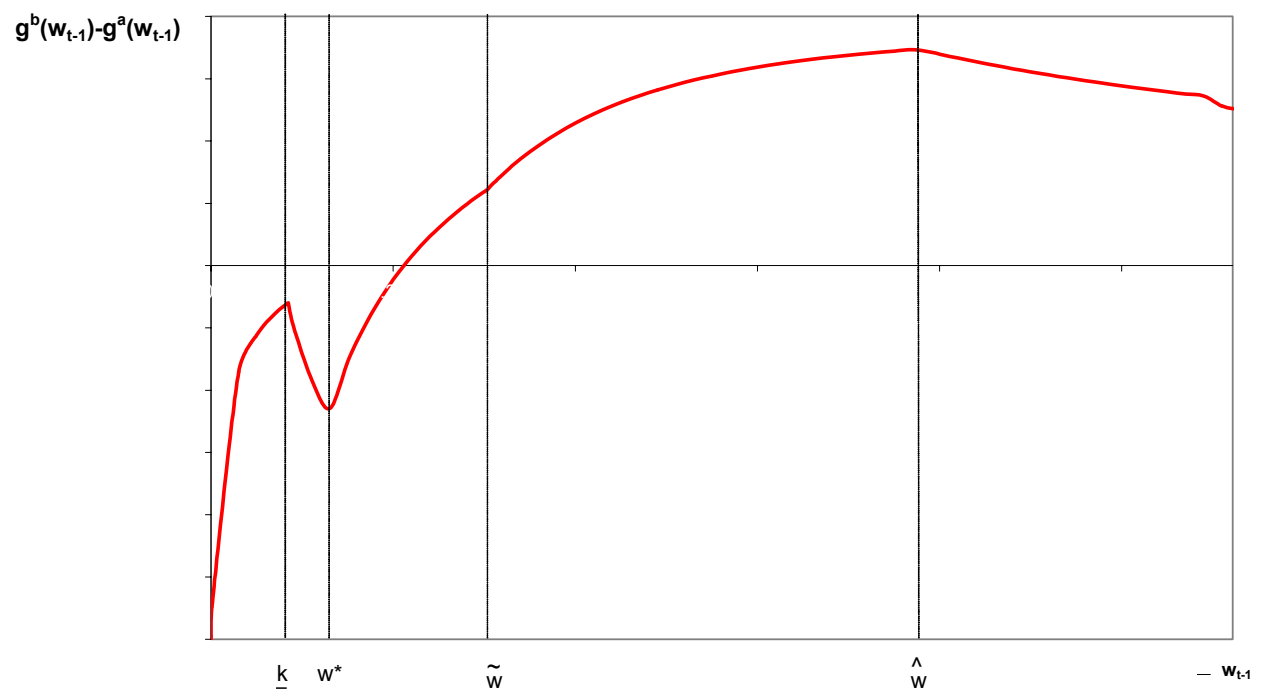

